\title{
Experimental Study on Mechanical Properties and Acoustic Emission Characteristics of Water Bearing Sandstone under Stable Cyclic Loading and Unloading
}

\author{
Xinzhan Qin, ${ }^{1}$ Yu Zhou ${ }^{1}{ }^{2,3}$ and Manchao $\mathrm{He}^{1}$ \\ ${ }^{1}$ State Key Laboratory of Geomechanics and Deep Underground Engineering, China University of Mining and Technology, \\ Beijing 100083, China \\ ${ }^{2}$ Complex Condition Drilling Experiment Center, Jilin University, Changchun 130012, China \\ ${ }^{3}$ Department of Civil, Environmental and Mining Engineering, University of Western Australia, 35 Stirling Hwy, Crawley, \\ WA 6009, Australia \\ Correspondence should be addressed to Yu Zhou; yu.zhou.19921105@gmail.com
}

Received 2 January 2020; Revised 18 April 2020; Accepted 1 June 2020; Published 28 July 2020

Academic Editor: Francisco Beltran-Carbajal

Copyright (C) 2020 Xinzhan Qin et al. This is an open access article distributed under the Creative Commons Attribution License, which permits unrestricted use, distribution, and reproduction in any medium, provided the original work is properly cited.

\begin{abstract}
Due to the adjustment of energy structure, a large number of coal mines are abandoned. Considering the environmental and economic effects, many experts proposed to use the abandoned mine cavern as the reservoir of the pumped storage power station. Furthermore, considering the long-term effects of repeated pumping and drainage and hydrodynamic pressure on the surrounding rock in coal mines, a large amount of sandstone was collected from the Ruineng coal mine in Yan'an city to carry out a series of laboratory tests. Through uniaxial compression testing of rock samples with different water content rates, combined with acoustic emission (AE) analysis, the strength softening and macrodeformation characteristics are obtained, and the influence of water content on acoustic emission characteristics is clarified. The mechanical properties of water bearing rock under cyclic loading and unloading experiments with varying upper limits are obtained using a triaxial test system, and the precursory information of rock failure is captured, providing significant guidance for stability analysis and instability warning for surrounding rock in pumped storage power stations.
\end{abstract}

\section{Introduction}

With the development of wind, solar, and nuclear power, demands for power adjustment are increasing [1-3]. Pumped storage power stations manage peak cutting, frequency modulation, and emergency standby of power; however, sites suitable for building water reservoirs are rare, and building cost should also be considered. Selection of the pumped storage power station location can be difficult [4]; therefore, it is imperative to find new nontraditional construction modes for pumped storage power stations, and the supporting key technologies need to be studied urgently [5].

Building pump power stations using abandoned mine roadways has significant environmental and social benefits [6]. The reason for the fact is that there are a large number of mines that have been abandoned due to the changing energy market in China. The number of abandoned coal mines in China is shown in Figure 1. Abandoned coal mines contain a roadway over a large area with some different height differences and sufficient water source, which are favorable conditions for pumped storage power station construction.

However, research on using abandoned mines as reservoirs for pumped storage power stations is relatively rare. The selection of station sites and the research of relevant equipment are still in the initial stage, and no relevant engineering examples exist. Therefore, relevant theoretical and experimental research should be carried out. During construction and operation, the coupling effect of stress and groundwater seepage results in changes in rock physical and mechanical properties, affecting construction safety and the 


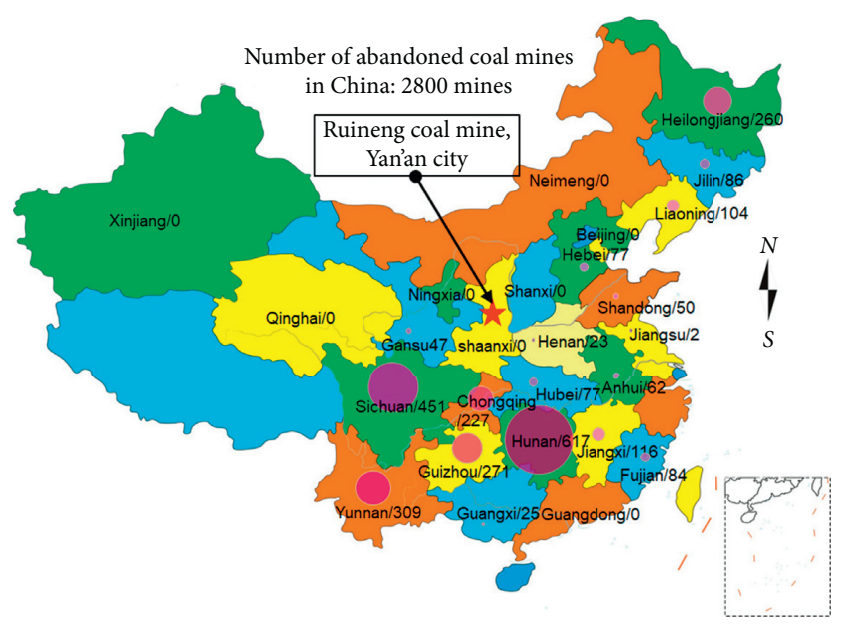

Figure 1: Distribution map of abandoned coal mines in China. Data from Energy Statistics Department of National Bureau of Statistics, China.

long-term stability of underground reservoirs [7-12]. During pumped storage power station operation, the repeated discharge and storage of water repeatedly impacts the surrounding rock, resulting in cyclic loading and unloading of the surrounding rock.

At present, scholars have conducted significant research on the mechanical properties of rock under cyclic loading and unloading [13-18]. Song et al. [19] carried out conventional uniaxial and uniaxial cyclic loading tests on three types of samples: coal, rock, and coal-rock combinations. The results showed that, compared with the conventional uniaxial loading condition, the maximum deformation before failure under the cyclic loading condition is greater, and Young's modulus increases quadratically with the cycle index. Meng et al. [20,21] conducted uniaxial cyclic loading and unloading tests on yellow sandstone, red sandstone, limestone, and marble by employing the MTS 815 rock mechanics test system. They analyzed and summarized the evolution law of cyclic acoustic emission of stress-strain changes of different rocks in loading and unloading stages. Pei and Yang et al. [22, 23] carried out triaxial cyclic loading and unloading tests of granite and deep-buried marble specimens under different confining pressures, respectively. The results show that the modulus of elasticity decreases with the loading and unloading cycles, while Poisson's ratio increases linearly. Liu et al. [24] studied the propagation of ultrasonic signal through coal under cyclic loading and unloading conditions. The result shows that when it progresses from the linear elastic stage to the elastic-plastic stage, the material inside the coal distorts and fractures more drastically, the inner defects are fully developed, and the acoustic parameters decrease significantly. Xu et al. [25] carried out a series of triaxial loading and unloading tests of sandstone samples under different stress conditions. Simultaneously, the AE characteristics of the failure precursors of sandstone samples were investigated. The result showed that the value of $\mathrm{AE}$ can predict rock failure at higher confining pressures. Zhao et al. [26] carried out short-term creep test of red sandstone under uniaxial incremental cyclic

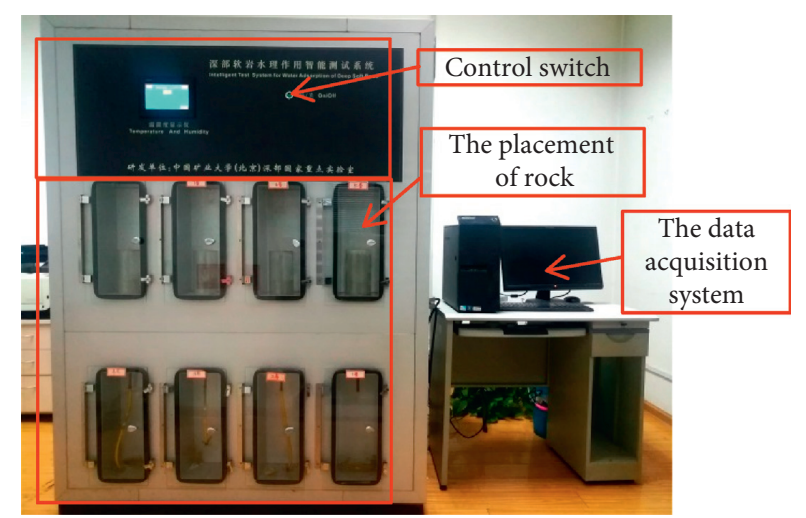

Figure 2: The deep soft rock absorption intelligent test system.

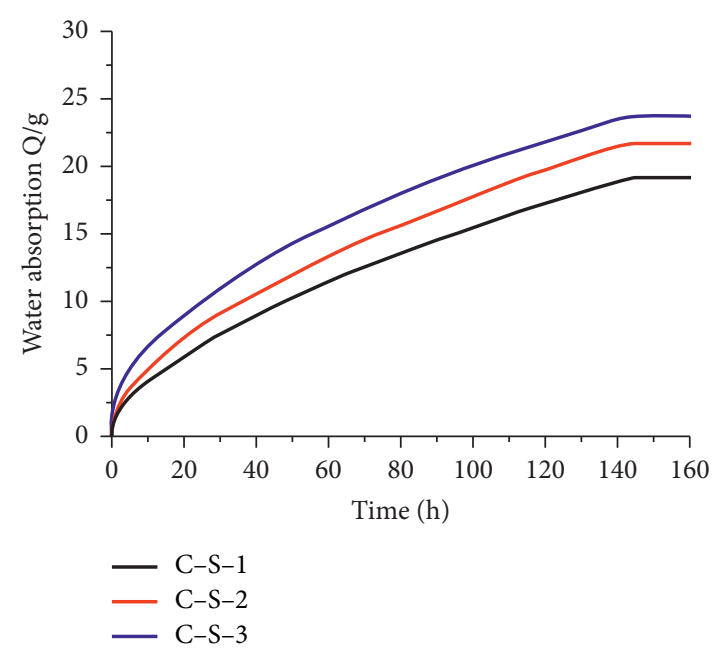

FIGURE 3: Water absorption characteristic curves for three sandstone samples.

compression and tension load and analyzed its deformation characteristics and energy dissipation. The test results show that the stress-strain curves in compression loading stage and tension loading stage have obvious memory effect. The creep curves can be divided into two stages: attenuation stage and stability stage. Chen et al. [27] studied the elasticplastic behavior of rock salt under cyclic loading-unloading condition and analyzed the strain development of rock in different loading stages. In 2016, He et al. [28] carried out strength and fatigue performance experimental study of complete sandstone specimen under dynamic cyclic loading with different loading frequency, loading amplitude, and loading speed. It was found that the fatigue life of sandstone decreases with loading speeds and amplitudes but increases with loading frequencies.

Most of the stress paths adopted by the above research are constant difference cyclic loading and unloading and staged cyclic loading and unloading, which are not suitable for the mechanical environment of water reservoirs. On the other hand, the internal joints, internal structure, physical state, and mechanical properties of rock will change after water absorption, which is easy to cause serious security risks $[29,30]$. In particular, some special rock masses have a good 


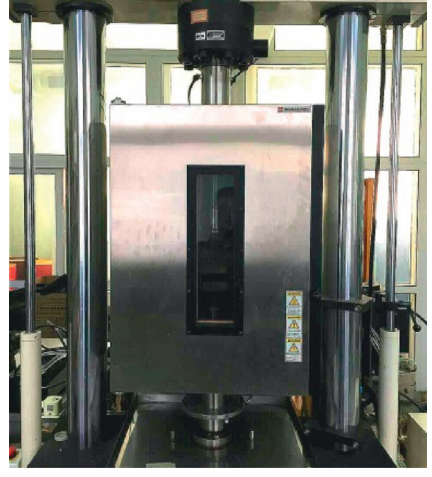

(a)

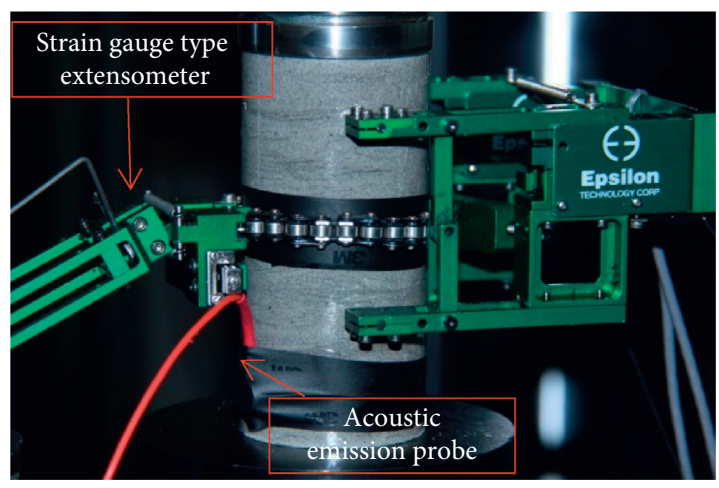

(b)

FIgURE 4: The XTR01 rock triaxial experimental system. (a) Microcomputer servo control triaxial testing machine. (b) Installation of strain gauge-type extensometer and acoustic emission probe.

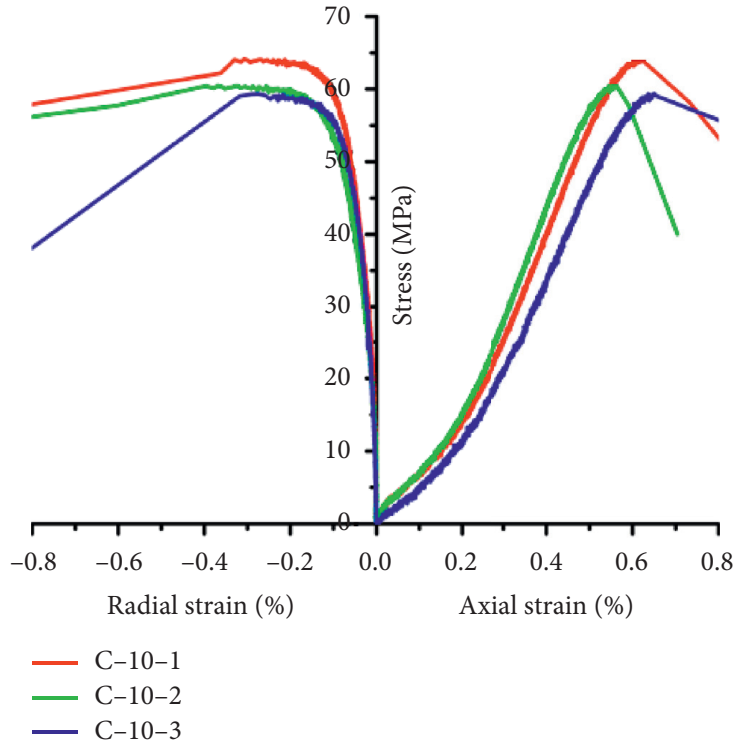

(a)

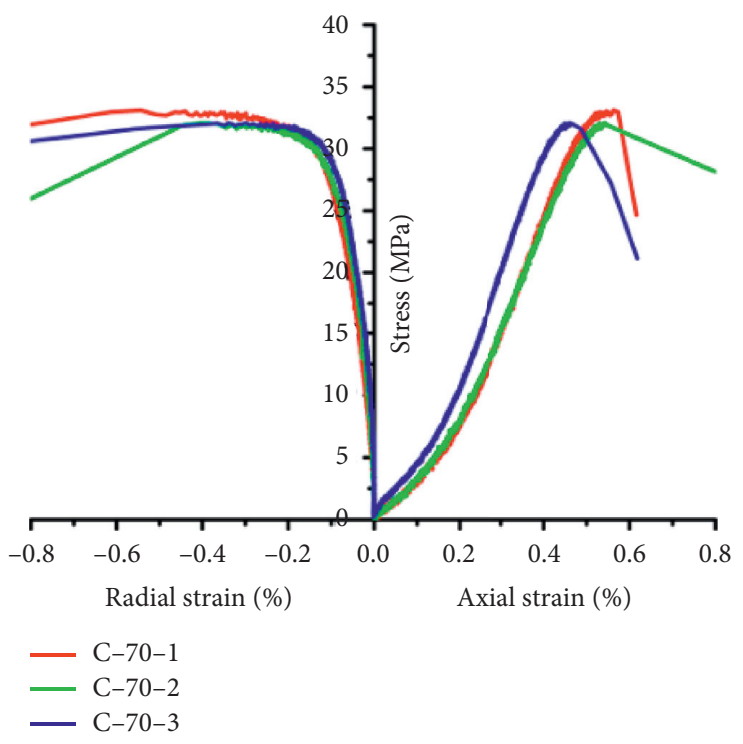

(c)

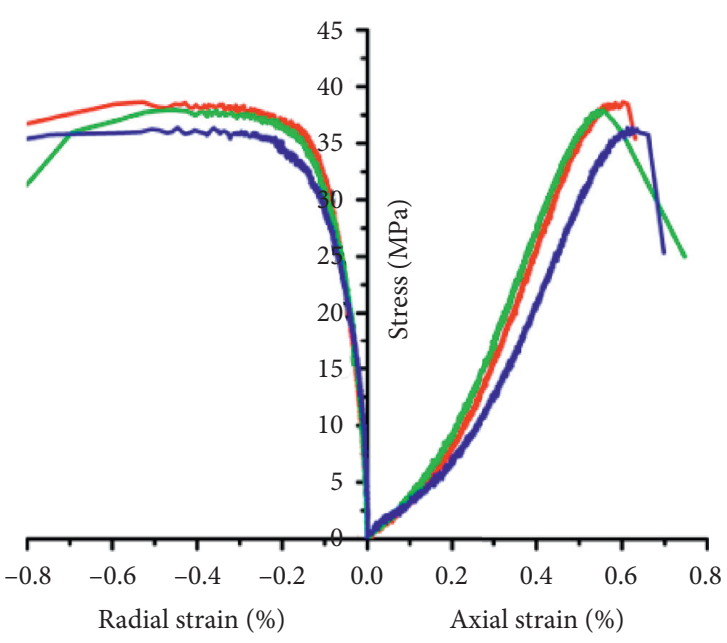

- C $-40-1$

- C $-40-2$

- C $-40-3$

(b)

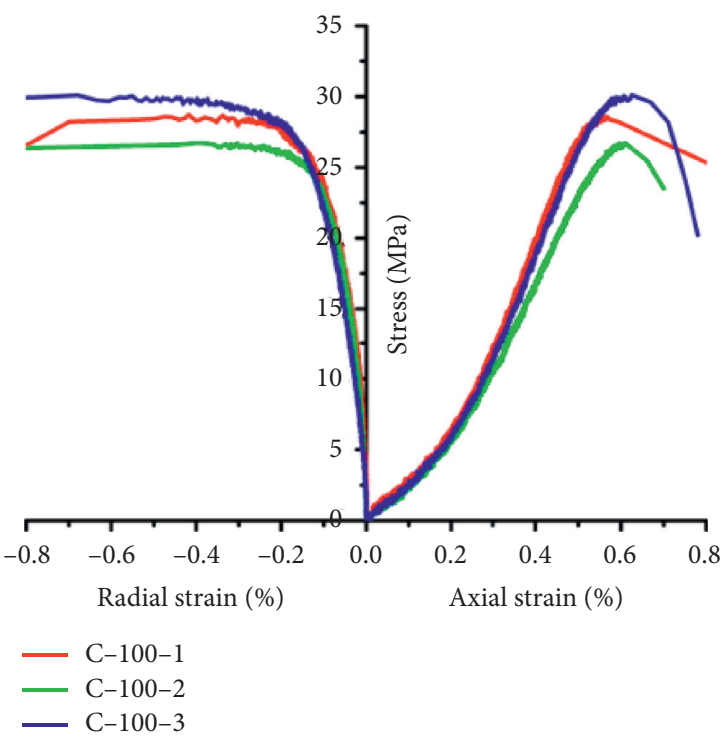

(d)

FIGURE 5: Complete stress-strain curves of sandstone samples with different water content rates. (a) C-10 rock group in the natural state. (b) C-40 rock group with $2.0 \%$ water content rate. (c) C-70 rock group with $3.5 \%$ water content rate. (d) C-100 rock group in the saturated rate. 
TABLE 1: The uniaxial compression experiment calculation results.

\begin{tabular}{|c|c|c|c|c|c|c|c|}
\hline $\begin{array}{l}\text { Test } \\
\text { number }\end{array}$ & $\begin{array}{c}\text { Water } \\
\text { content rate }\end{array}$ & $\begin{array}{c}\text { Uniaxial } \\
\text { compressive } \\
\text { strength, } \sigma_{c}(\mathrm{MPa}) \\
\end{array}$ & $\begin{array}{c}\text { Average uniaxial } \\
\text { compressive strength, } \\
\sigma_{c}(\mathrm{MPa})\end{array}$ & $\begin{array}{c}\text { Elastic } \\
\text { modulus, } E \\
(\mathrm{GPa})\end{array}$ & $\begin{array}{c}\text { Average elastic } \\
\text { modulus, } E \\
(\mathrm{GPa}) \\
\end{array}$ & $\begin{array}{c}\text { Poisson's } \\
\text { ratio, } v\end{array}$ & $\begin{array}{l}\text { Average } \\
\text { Poisson's } \\
\text { ratio, } v\end{array}$ \\
\hline $\begin{array}{l}\text { C-10-1 } \\
\text { C-10-2 } \\
\text { C- } 10-3 \\
\end{array}$ & $\begin{array}{c}0.5 \% \text { (natural } \\
\text { state) }\end{array}$ & $\begin{array}{l}64.149 \\
60.505 \\
59.350 \\
\end{array}$ & 61.334 & $\begin{array}{l}122.250 \\
127.438 \\
128.079\end{array}$ & 125.922 & $\begin{array}{l}0.128 \\
0.170 \\
0.174\end{array}$ & 0.157 \\
\hline $\begin{array}{l}\text { C- } 40-1 \\
\text { C- } 40-2 \\
\text { C- } 40-3 \\
\end{array}$ & $2.0 \%$ & $\begin{array}{l}38.630 \\
37.960 \\
36.380 \\
\end{array}$ & 37.657 & $\begin{array}{l}95.404 \\
95.900 \\
87.589 \\
\end{array}$ & 92.964 & $\begin{array}{l}0.358 \\
0.333 \\
0.321 \\
\end{array}$ & 0.338 \\
\hline $\begin{array}{l}\mathrm{C}-70-1 \\
\mathrm{C}-70-2 \\
\mathrm{C}-70-3\end{array}$ & $3.5 \%$ & $\begin{array}{l}33.110 \\
32.081 \\
32.075\end{array}$ & 32.422 & $\begin{array}{l}85.450 \\
83.078 \\
86.034 \\
\end{array}$ & 84.854 & $\begin{array}{l}0.394 \\
0.390 \\
0.401\end{array}$ & 0.395 \\
\hline $\begin{array}{l}\text { C-100-1 } \\
\text { C-100-2 } \\
\text { C-100-3 }\end{array}$ & $\begin{array}{c}5 \% \\
\text { (saturated } \\
\text { state) }\end{array}$ & $\begin{array}{l}28.720 \\
26.734 \\
30.101\end{array}$ & 28.518 & $\begin{array}{l}77.230 \\
79.122 \\
71.553\end{array}$ & 75.968 & $\begin{array}{l}0.445 \\
0.429 \\
0.444\end{array}$ & 0.439 \\
\hline
\end{tabular}

integrity and a certain bearing capacity in the natural state, but they will expand, soften, or even collapse after encountering water, which will reduce the strength of rock mass [31-37]. Thus, it is significant to investigate the mechanical properties of water bearing sandstone under stable cyclic loading and unloading condition.

In this work, sandstone samples were collected from the roadway floor of the Ruineng coal mine in Yan'an city, the strength softening and acoustic emission characteristics of the sandstone samples with different amounts of absorbed water were researched, and the softening strength dividing point was determined. Relevant cyclic loading and unloading experiments were carried out for the sandstone in the roadway floor, and the mechanical and acoustic emission characteristics of the surrounding rock under stable cycle loading and unloading with varying maximum loading stress were studied, laying the theoretical support for the reinforcement and stability evaluation of the surrounding rock near pumped storage power stations in abandoned mines.

\section{Rock Water Absorption Experiment}

2.1. Rock Sample Selection. Reservoir pumped storage power stations should be built on a roadway with stable rock strata, and the surrounding rock should be able to bear cyclic loading and unloading after absorbing water. The sandstones in the roadway floor of the Ruineng coal mine are selected in this experiment. Cylindrical rock samples are $\varnothing$ $50 \mathrm{~mm} \times 100 \mathrm{~mm}( \pm 1 \mathrm{~mm})$ and are divided into two groups for uniaxial compression testing and cyclic loading and unloading testing.

2.2. Experimental Equipment and Process. The water absorption experiment was carried out using the deep soft rock absorption intelligent test system (see Figure 2). There are four nonpressure water absorption boxes on the upper layer and four pressure water absorption boxes on the lower layer. The measuring equipment on the upper left is used to control and observe the humidity and temperature inside the box. The back of the system contains a weighing system composed of eight high-precision electronic balances connected to a

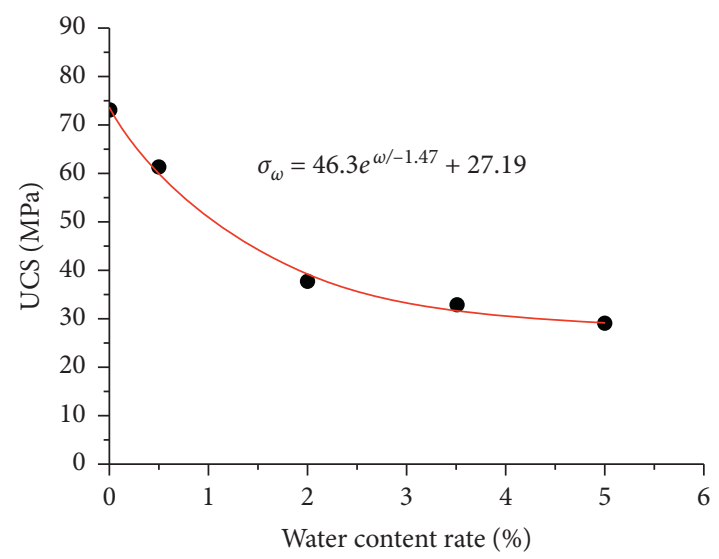

Figure 6: Strength softening fit curve of sandstone samples.

computer with the data acquisition system. Water absorption data from the rock samples can be displayed in real time, and the data are collected to make the water absorption characteristics curve of sandstone. The water absorption characteristics of three samples are presented in Figure 3.

In the initial stage of water absorption, the tangent gradients of the water absorption curve at each time point are relatively large, and the change rate of the gradient is relatively large, indicating that the water content is larger but unstable (see Figure 3). After a period of time, the water content gradually stabilizes and decreases. In the later water absorption stage, the curve is almost horizontal, indicating that the sample is saturated. Using the boiling method, the true saturated water absorption of these sandstone samples was obtained. The average natural water absorption is $0.52 \%$, and the average true saturated water absorption is $5.2 \%$.

\section{Uniaxial Compressive Strength Test of Rocks with Different Water Content Rates}

3.1. Experimental Process. The uniaxial compressive strength test was carried out using a XTR01 rock triaxial experimental system (see Figure 4). Its maximum load is $\pm 200 \mathrm{KN}$ in the dynamic state and $\pm 300 \mathrm{KN}$ in the static state; the maximum 

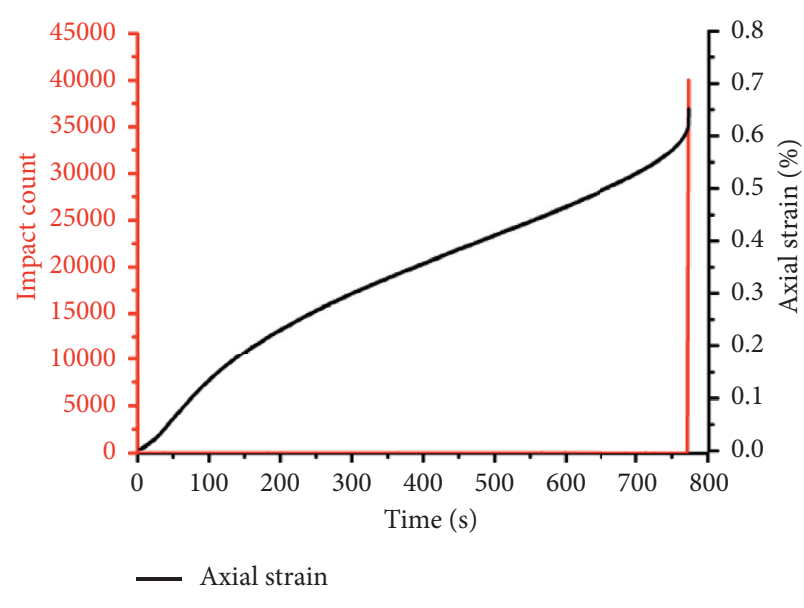

— Impact count

(a)

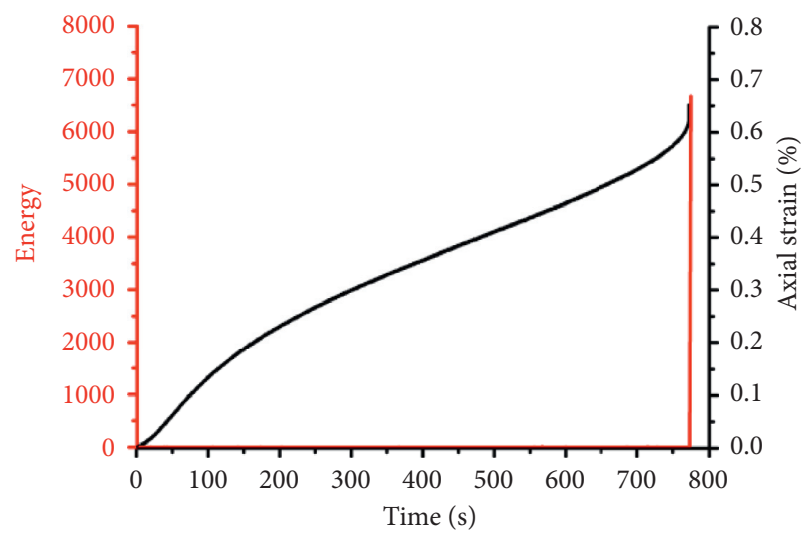

— Axial strain
Energy

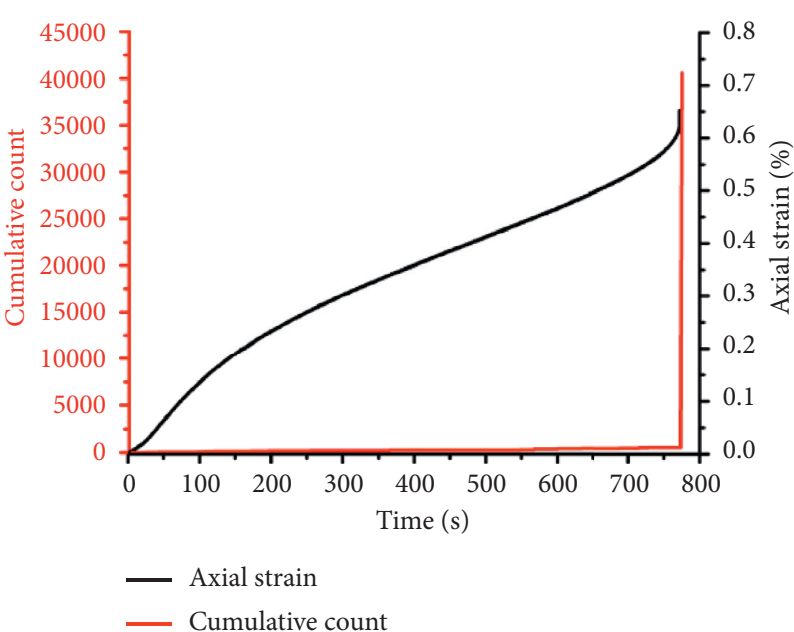

(b)

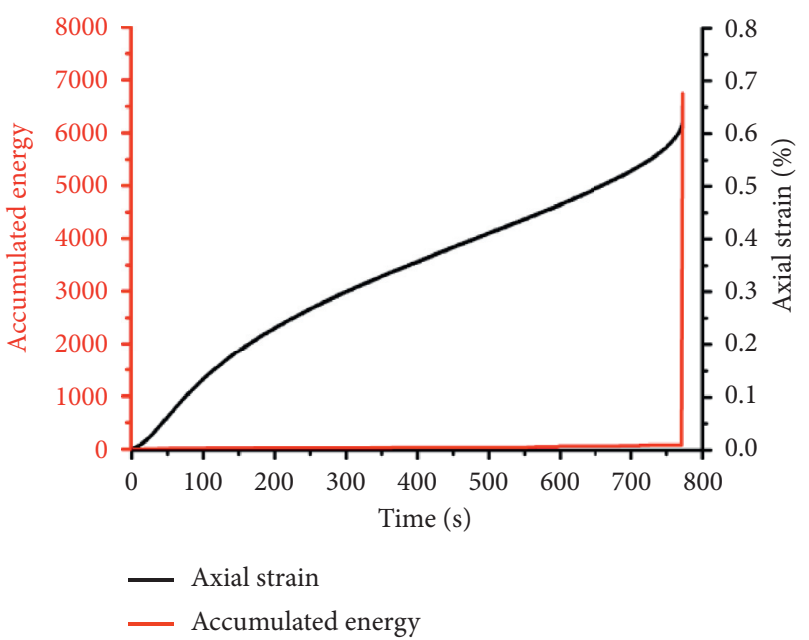

(d)

Figure 7: Deformation and acoustic emission characteristics of C-10-1 sample. (a) The curves of ringing count and axial strain of C-10-1 sample with time. (b) The curves of cumulative ringing count and axial strain of C-10-1 sample with time. (c) The curves of energy and axial strain of C-10-1 sample with time. (d) The curves of cumulative energy and axial strain of C-10-1 sample with time.

stroke is $\pm 50 \mathrm{~mm}$; and the loading frequency ranges from 0.00001 to $100 \mathrm{~Hz}$.

In the experiment, the PCI-2 software system is used for acoustic emission acquisition. The system has a frequency range of $1-3 \mathrm{MHz}$. The PCI-2 acquisition system is equipped with a broadband sensor, with a sampling frequency of $1 \mathrm{Msps}$ and a frequency response range of $100 \mathrm{~Hz}-1 \mathrm{MHz}$. The transient recording and acquisition system can be used to capture transient signals at high speed and replay them at low speed, so that the spectrum of acoustic emissions in the $100 \mathrm{~Hz}-1 \mathrm{MHz}$ frequency band can be truly measured and analyzed.

Sensors are fixed $30 \mathrm{~mm}$ away from the lower end face of sample using a rubber belt, and petroleum jelly is used to connect the sample and the sensor to ensure that the sensor clearly receives the acoustic emission signals. The threshold value of the acoustic emission test and analysis system is $35 \mathrm{~dB}$, the main amplifier is $40 \mathrm{~dB}$, and the sampling frequency is $1 \mathrm{MHz}$.

\subsection{Experimental Result Analysis}

3.2.1. Physical and Mechanical Properties Analysis of Sandstone with Different Water Content Rates. To examine the physical and mechanical properties of sandstone with different water content rates, four sample groups (C-10 group, C-40 group, C-70 group, and C-100 group) were selected for uniaxial compressive strength testing. Each group includes three sandstone samples. The water content rate of group C- 10 is $0.5 \%$ (natural state), the water content rate of group C- 40 is $2 \%$, the water content rate of group $\mathrm{C}-70$ is $3.5 \%$, and the water content rate of group C-100 is $5 \%$ (saturated water absorption state). The uniaxial compression stress-strain curves are shown in Figure 5.

The compression failure process of the samples undergoes the three steps: (I) gradual compaction; (II) elastic deformation; (III) plastic deformation and failure. Under gradual compaction, with the continuous increase of axial pressure, the stress-strain curve shows a "concave" growth, 

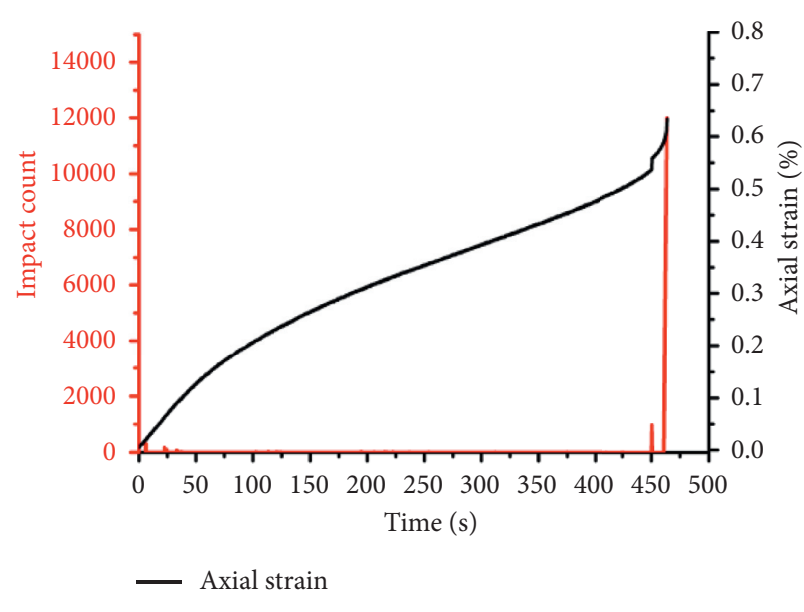

- Impact count

(a)

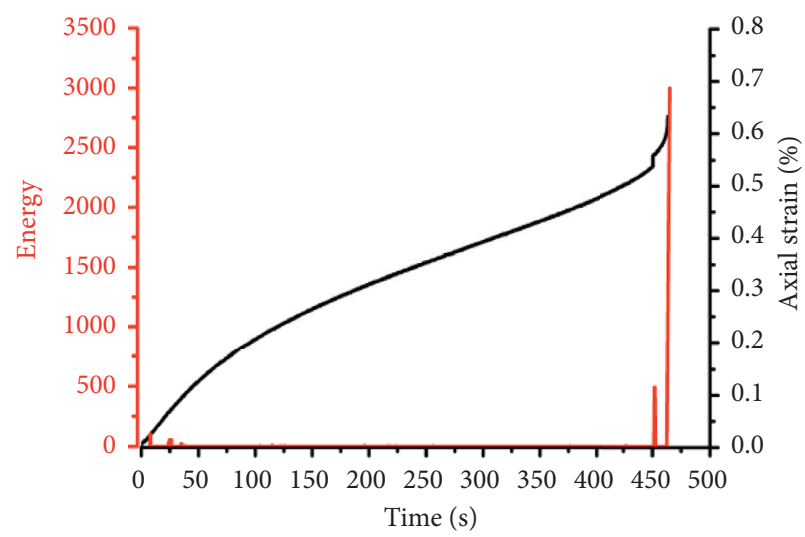

- Axial strain
Energy

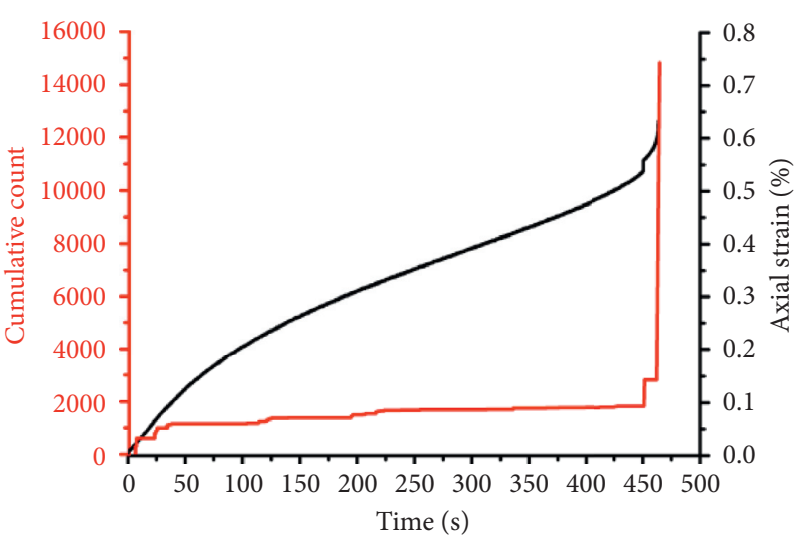

- Axial strain

_ Cumulative count

(b)

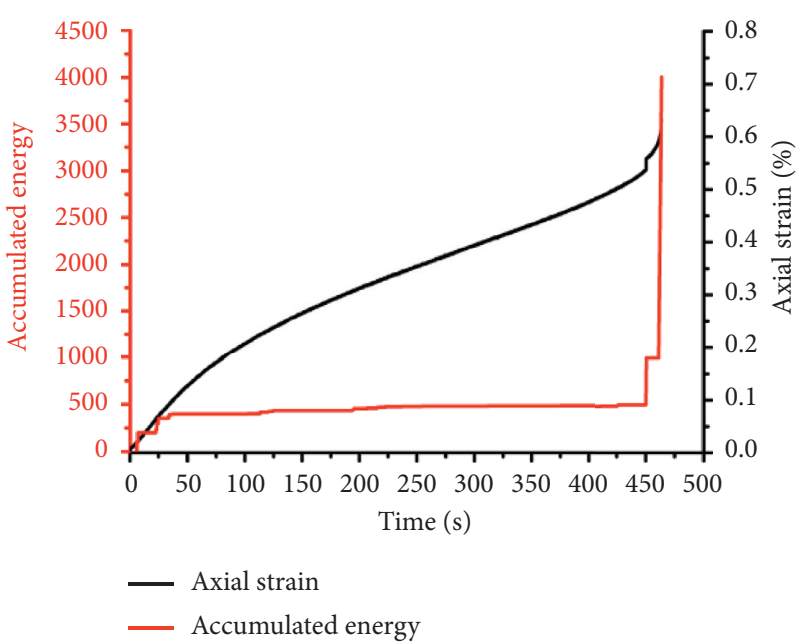

(d)

(c)

FIGURE 8: Deformation and acoustic emission characteristics of C-40-1 sample. (a) The curves of ringing count and axial strain of C-40-1 sample with time. (b) The curves of cumulative ringing count and axial strain of C-40-1 sample with time. (c) The curves of energy and axial strain of C-40-1 sample with time. (d) The curves of cumulative energy and axial strain of C-40-1 sample with time.

the curve gradient increases gradually, and the change in cumulative strain caused by stress decreases gradually. Fractures and microfissures inside the sample are gradually closed, and sample density increases. During elastic deformation, the specimen remains in a stable state after the gradual compaction stage. The stress-strain curve is approximately a straight line, and the slope of the line is the elastic modulus of the sandstone sample. During plastic deformation and failure, with increasing axial stress, the curve changes from approximately linear to convex. The stress at the inflection point is the yield stress of the sandstone sample, and the hysteresis curve shows a sharp drop. In this stage, new cracks are formed and develop gradually, and the rock mass becomes unstable and undergoes plastic deformation until the sample is destroyed.

The results of uniaxial compression experiment are shown in Table 1. According to Table 1, the uniaxial compressive strength fitting curve for rocks with different water content rates is deduced in Figure 6.
The effects of water content rate on sandstone uniaxial compressive strength are significant (see Figure 6). With increasing water content rate, the uniaxial compressive strength shows a significant decreasing trend. The uniaxial compressive strength of sandstone samples in the natural state $(0.5 \%$ water content rate) is large. As the water content rate of samples reaches saturation, sample strength decreases to a relatively small value. The predicted strength softening dividing point for sandstone samples is $2 \%$ water content rate. Strength softening of sandstone samples is most obvious when the water content rate is between $0.5 \%$ and $2 \%$. After the water content rate exceeds $2 \%$, the strength softening phenomenon is significantly alleviated.

3.2.2. Acoustic Emission Characteristics Analysis of Sandstone with Different Water Content Rates. In this test, the mechanical parameters, acoustic emission parameters, and waveform signals collected by the acoustic emission data 

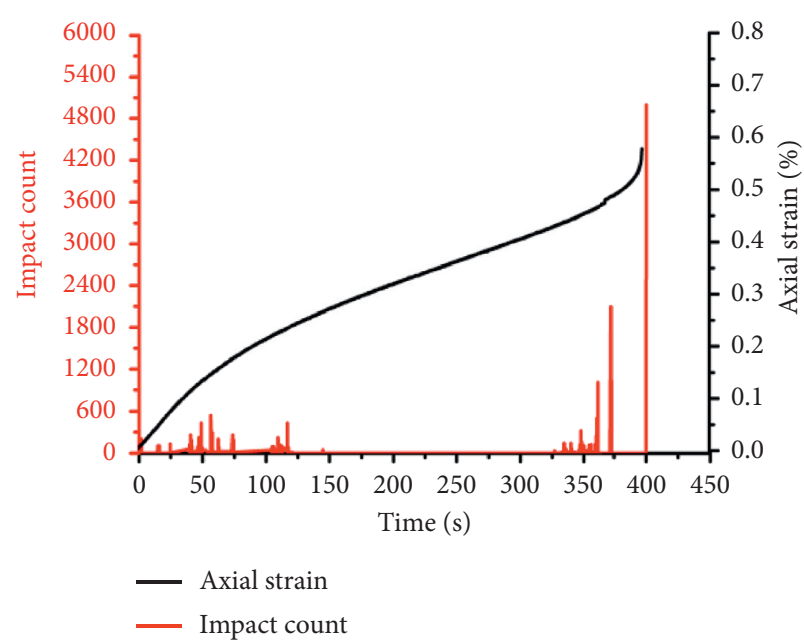

(a)
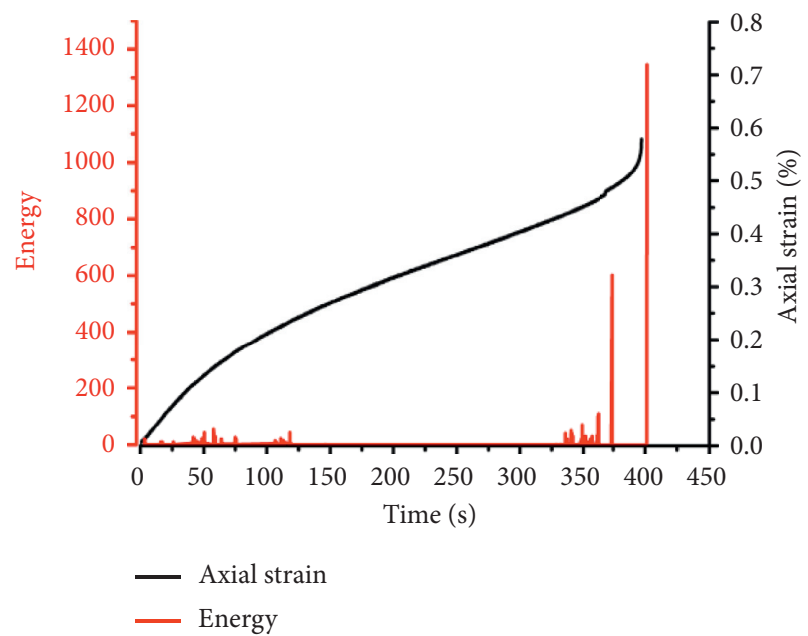

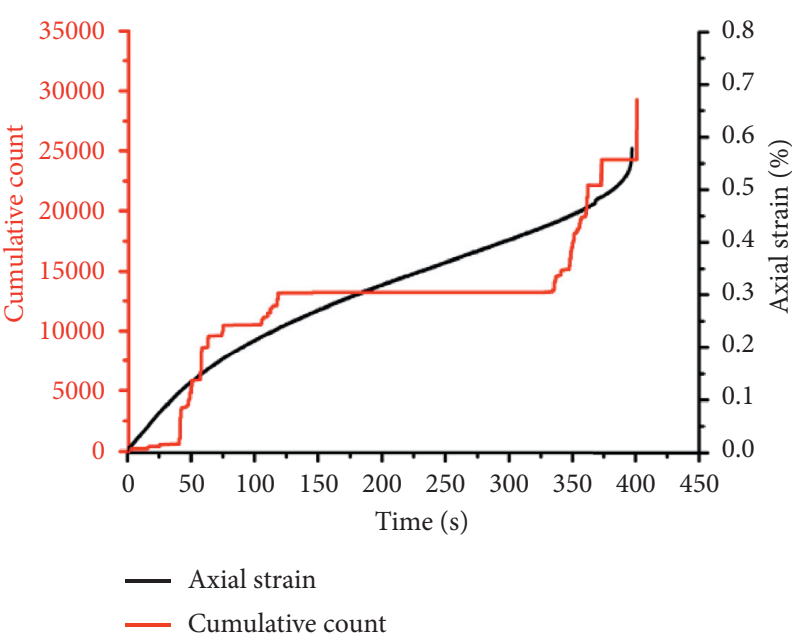

(b)

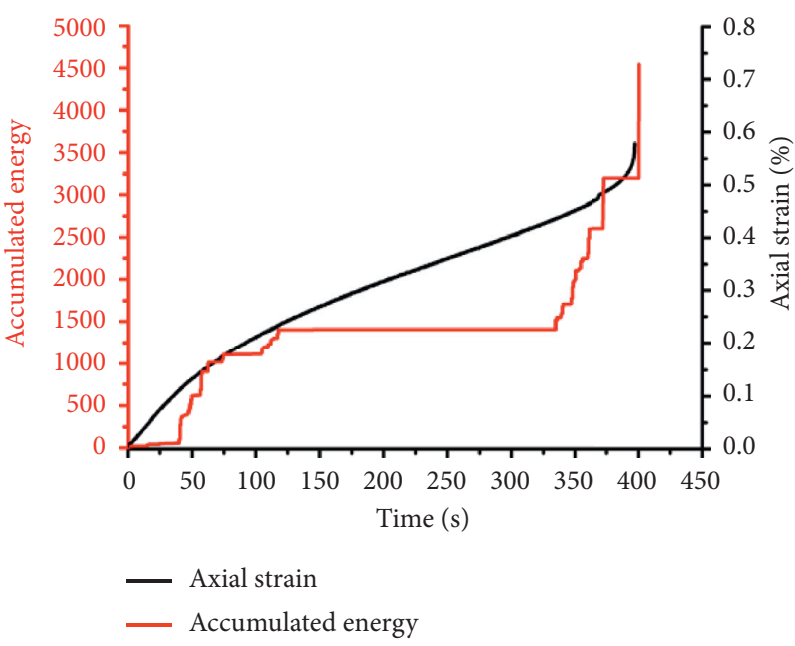

(d)

FIGURE 9: Deformation and acoustic emission characteristics of C-70-1 sample. (a) The curves of ringing count and axial strain of C-70-1 sample with time. (b) The curves of cumulative ringing count and axial strain of C-70-1 sample with time. (c) The curves of energy and axial strain of C-70-1 sample with time. (d) The curves of cumulative energy and axial strain of C-70-1 sample with time.

acquisition system are analyzed. Because the evolution characteristics of each group are similar, the acoustic emission characteristics from representative specimens are shown in Figures 7-10.

(1) Sandstone in the natural state

(2) Sandstone with $2.0 \%$ water content rate

(3) Sandstone with $3.5 \%$ water content rate

(4) Sandstone in the saturated state

The acoustic emission ring count of samples in the natural state in the first and second stages is relatively small (see Figures 7-10). With increasing water content rate, the acoustic emission activities of specimens in the first and second stages increase and gradually appear more continuous with a uniform distribution, indicating that, after the sample absorbs water, the physical properties of the cemented material have changed, and the structural plane inside the rock undergoes slip, weakening the rock. A certain amount of acoustic emission activity is produced due to particle breakage, friction, and sliding of the structural surface and microcrack development.

The AE count in the second stage is slightly less than that in the first stage, and the cumulative count of $\mathrm{AE}$ is approximately a straight line, indicating that the microcracks inside the sample are in a relatively stable and slow development stage. In the third stage, ring count increases rapidly. Several peaks are present, corresponding to the inflexion points on the strain curve. The specimen produces new cracks and enters the crack propagation failure stage. At the moment of failure, ring count reaches its maximum value, and the cumulative ring count increases rapidly, showing multiple steps. With increasing water content rate, acoustic emissions are slightly delayed compared to the peak stress position, and the precursory information of rock destruction becomes less and less obvious, which shows that increasing water content rate changes the rock failure mode, affecting the accuracy of acoustic emission prediction. 

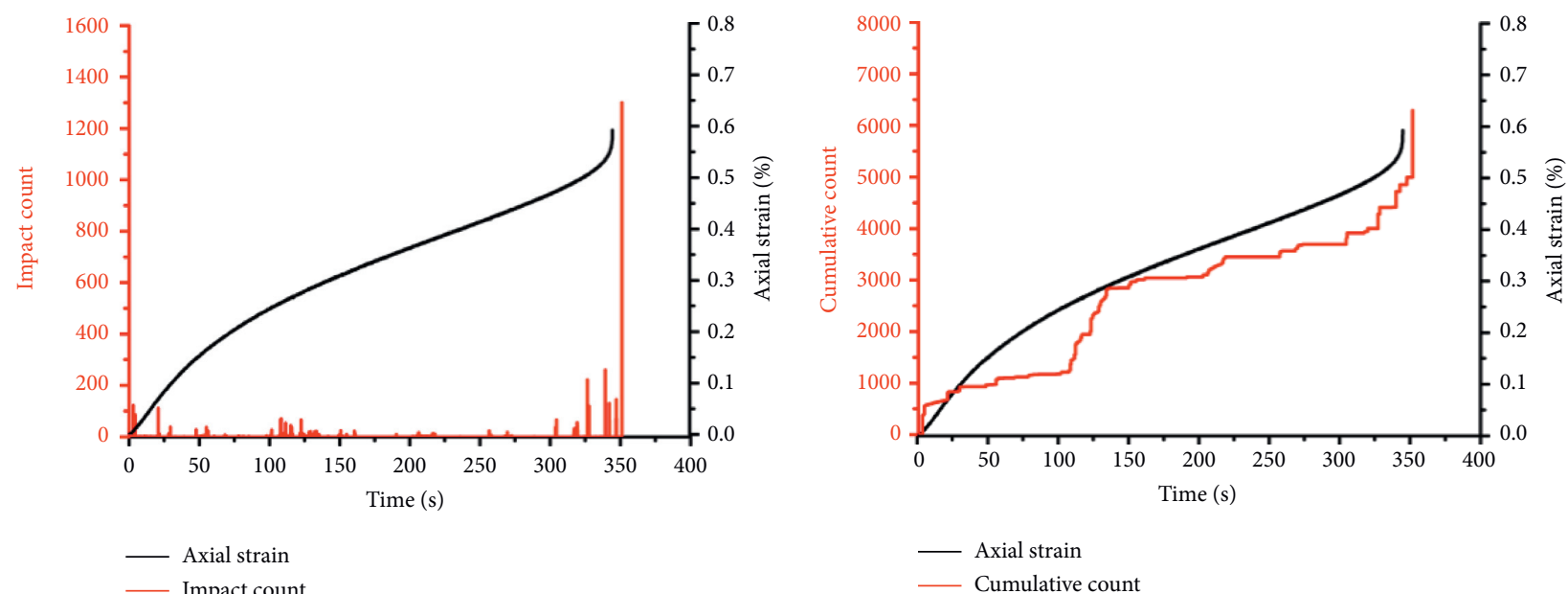

(a)

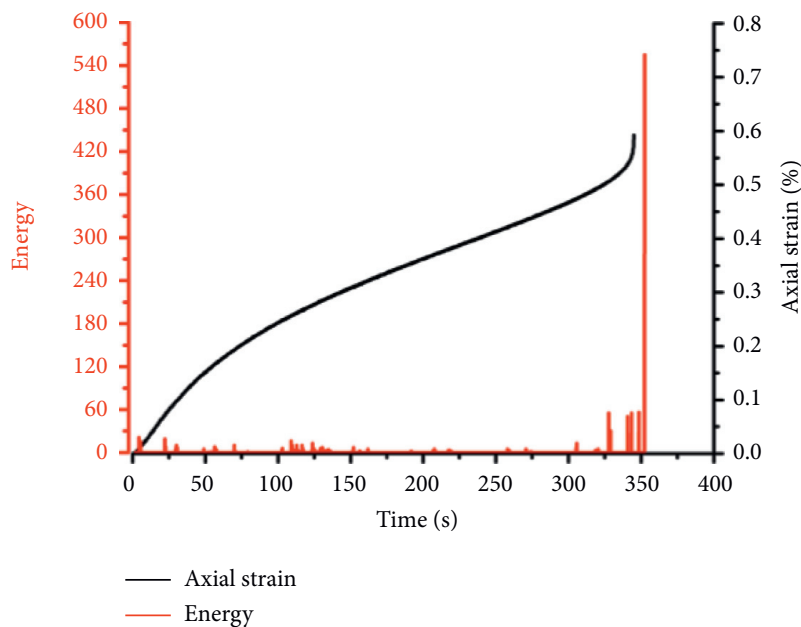

(c)

(b)

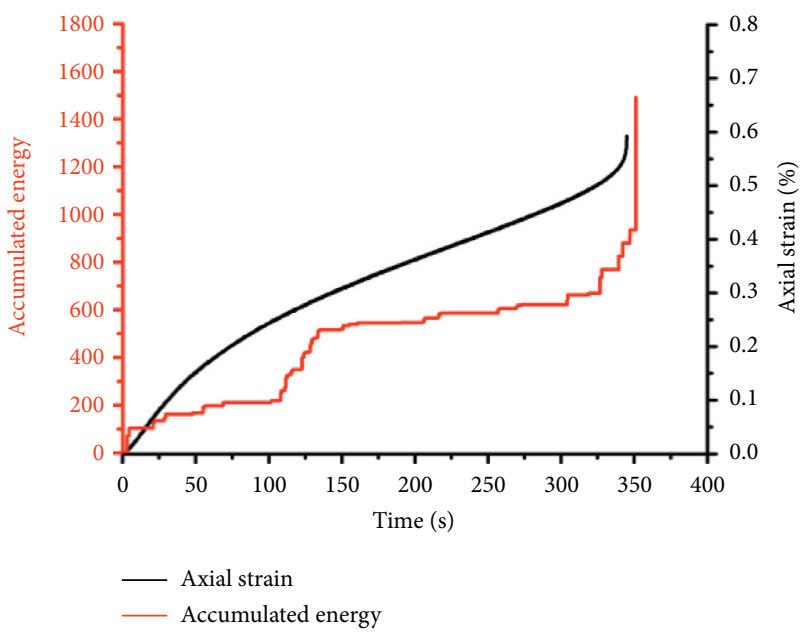

(d)

FIGURE 10: Deformation and acoustic emission characteristics of C-100-1 sample. (a) The curves of ringing count and axial strain of C-100-1 sample with time. (b) The curves of cumulative ringing count and axial strain of C-100-1 sample with time. (c) The curves of energy and axial strain of C-100-1 sample with time. (d) The curves of cumulative energy and axial strain of C-100-1 sample with time.

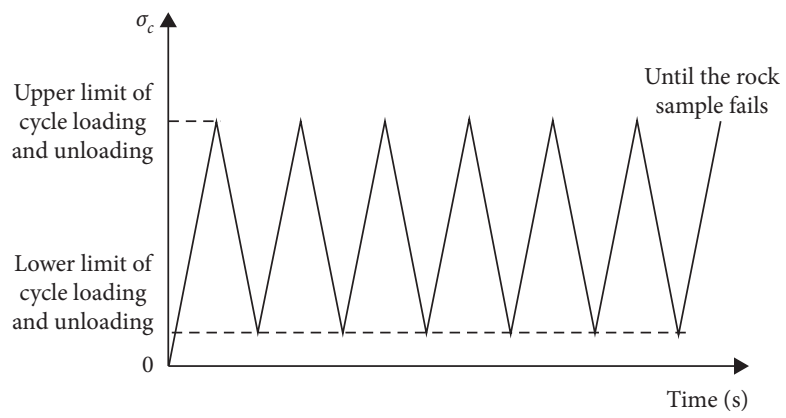

FIGURE 11: Stable cyclic loading and unloading path.

With increasing water content rate, the count maximum and cumulative counts of acoustic emission (AE) decrease, i.e., natural state count $>2.0 \%$, water content rate count $>3.5 \%$, and water content rate count $>$ saturated state count.
With increasing water content rate, the acoustic emission activity at the beginning of loading is more obvious, while the position of AE peak is gradually delayed compared to the position of the strain mutation point. 


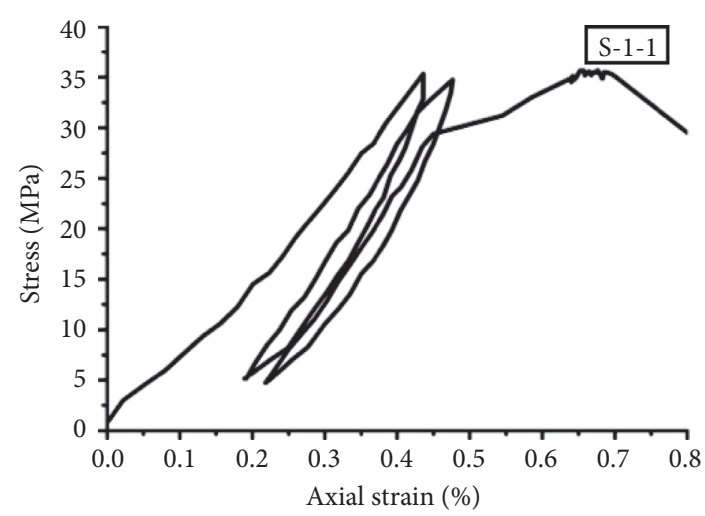

(a)

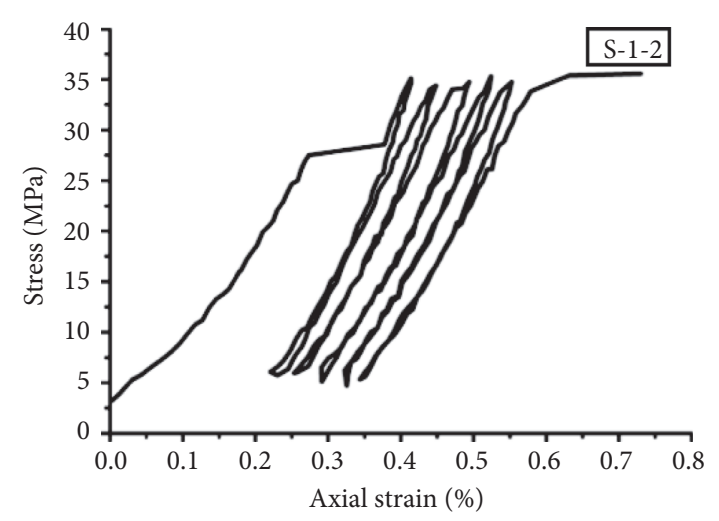

(b)

FIGURE 12: The stress-strain curves of S-1 rock sample group under cyclic loading and unloading (5-35 MPa). (a) S-1-1 sample. (b) S-1-2 sample.

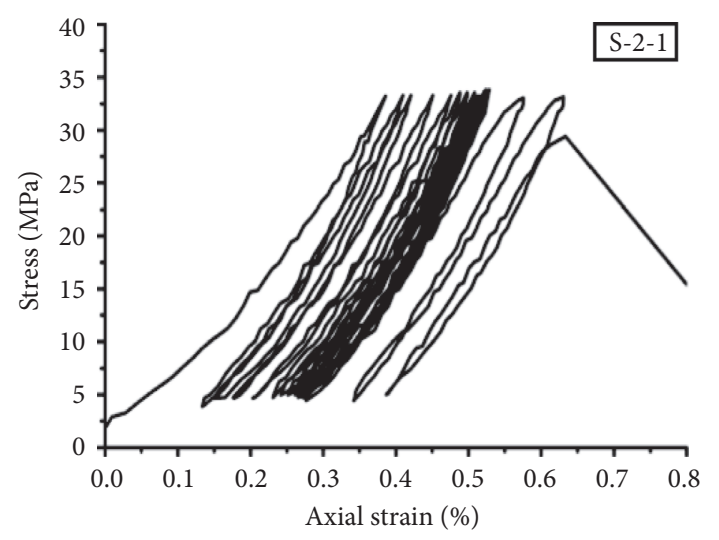

(a)

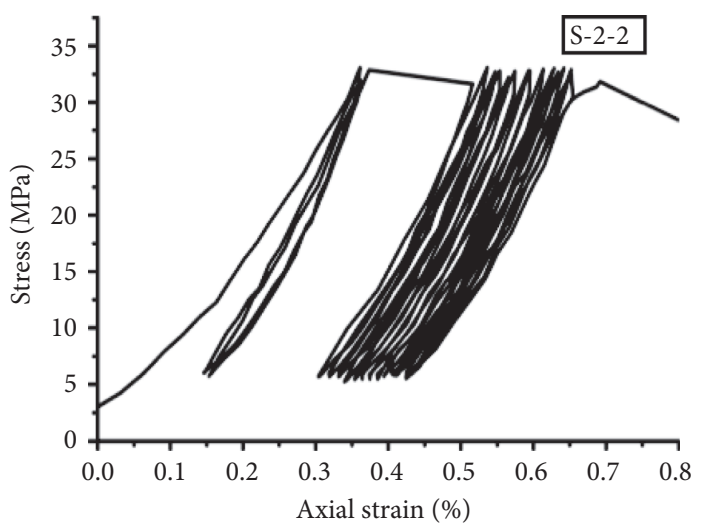

(b)

Figure 13: The stress-strain curves of S-2 rock sample group under cyclic loading and unloading (5-33.5 MPa). (a) S-2-1 sample. (b) S-2-2 sample.

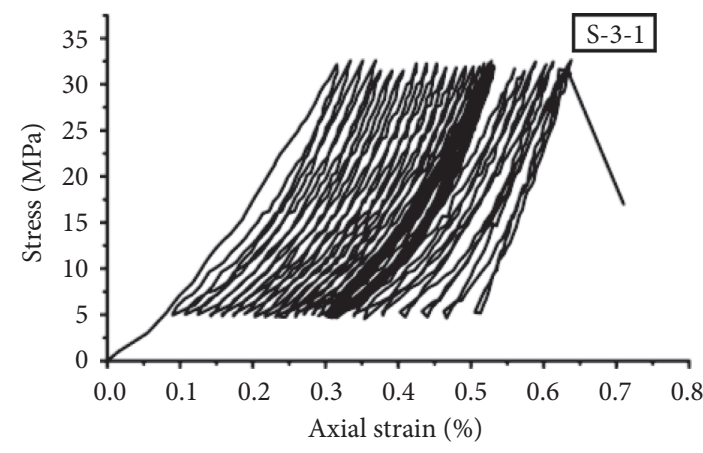

(a)

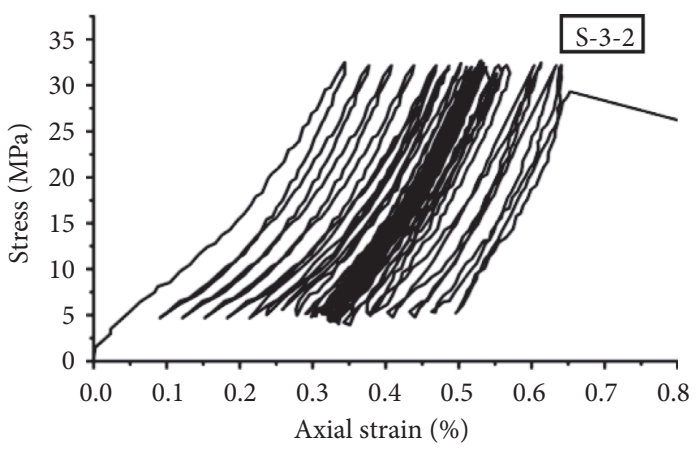

(b)

Figure 14: The stress-strain curves of S-3 rock sample group under cyclic loading and unloading (5-32 MPa). (a) S-3-1 sample. (b) S-3-2 sample. 
TABLE 2: Test results of rock samples under uniaxial cyclic loading and unloading.

\begin{tabular}{|c|c|c|c|c|c|c|}
\hline $\begin{array}{l}\text { Test } \\
\text { number }\end{array}$ & $\begin{array}{c}\text { Lower stress limit } \\
(\mathrm{MPa})\end{array}$ & $\begin{array}{c}\text { Upper stress limit } \\
(\mathrm{MPa})\end{array}$ & $\begin{array}{l}\text { Cycle number } \\
\text { (time) }\end{array}$ & $\begin{array}{l}\text { Average cycle } \\
\text { number (time) }\end{array}$ & $\begin{array}{l}\text { Strain of rock } \\
\text { failure }\left(10^{-3}\right)\end{array}$ & $\begin{array}{l}\text { Average strain of rock } \\
\text { failure }\left(10^{-3}\right)\end{array}$ \\
\hline S-1-1 & & & 2 & & 7.17 & \\
\hline S-1-2 & & & 5 & & 7.48 & \\
\hline S-1-3 & 5 & 35 & 3 & 3.8 & 7.42 & 7.402 \\
\hline S-1-4 & & & 5 & & 7.55 & \\
\hline S-1-5 & & & 4 & & 7.39 & \\
\hline S-2-1 & & & 19 & & 6.72 & \\
\hline S-2-2 & & & 19 & & 6.92 & \\
\hline S-2-3 & 5 & 33.5 & 23 & 19.6 & 6.84 & 6.812 \\
\hline S-2-4 & & & 17 & & 6.76 & \\
\hline S-2-5 & & & 20 & & 6.82 & \\
\hline S-3-1 & & & 43 & & 6.41 & \\
\hline S-3-2 & & & 33 & & 6.60 & \\
\hline S-3-3 & 5 & 32 & 37 & 38.4 & 6.57 & 6.494 \\
\hline S-3-4 & & & 40 & & 6.46 & \\
\hline S-3-5 & & & 39 & & 6.43 & \\
\hline
\end{tabular}

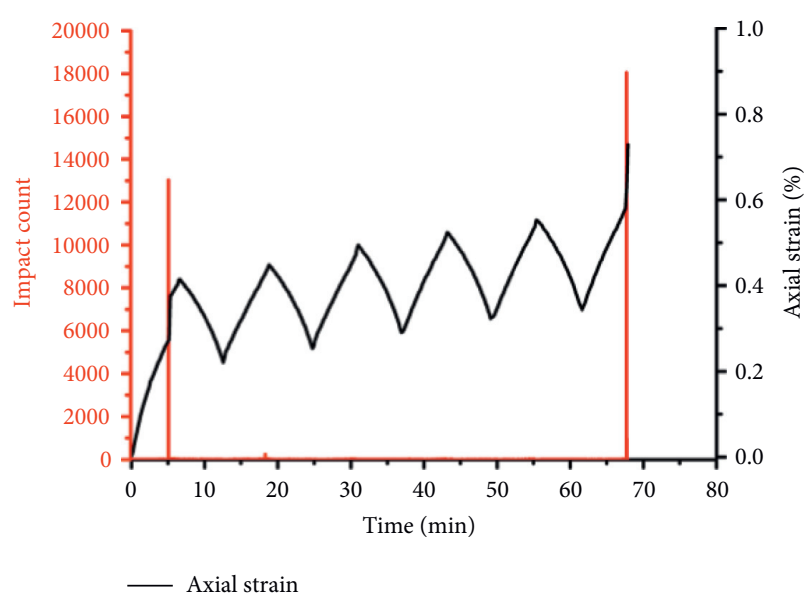

(a)

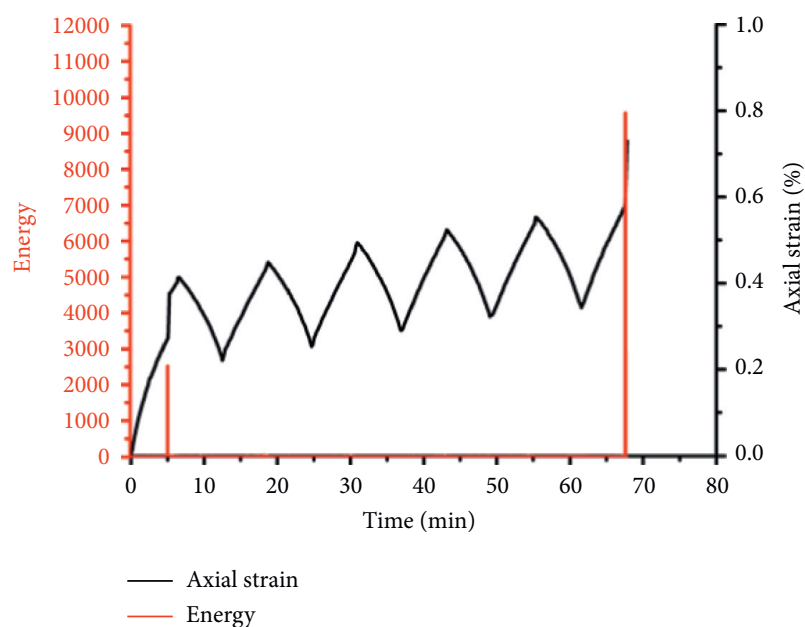

(c)

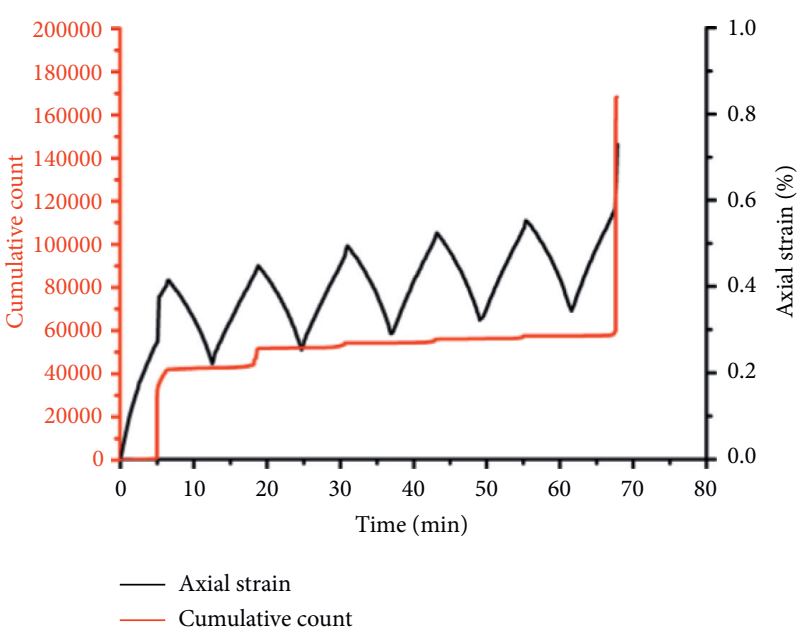

(b)

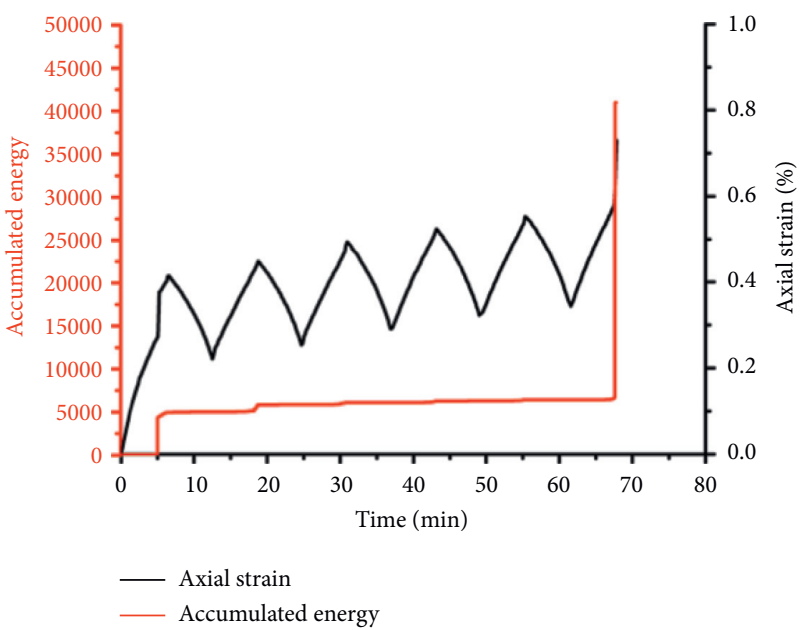

(d)

Figure 15: Deformation and acoustic emission characteristics of S-1-2 sample. (a) The curves of ringing count and axial strain of S-1-2 sample with time. (b) The curves of cumulative ringing count and axial strain of S-1-2 sample with time. (c) The curves of energy and axial strain of S-1-2 sample with time. (d) The curves of cumulative energy and axial strain of S-1-2 sample with time. 


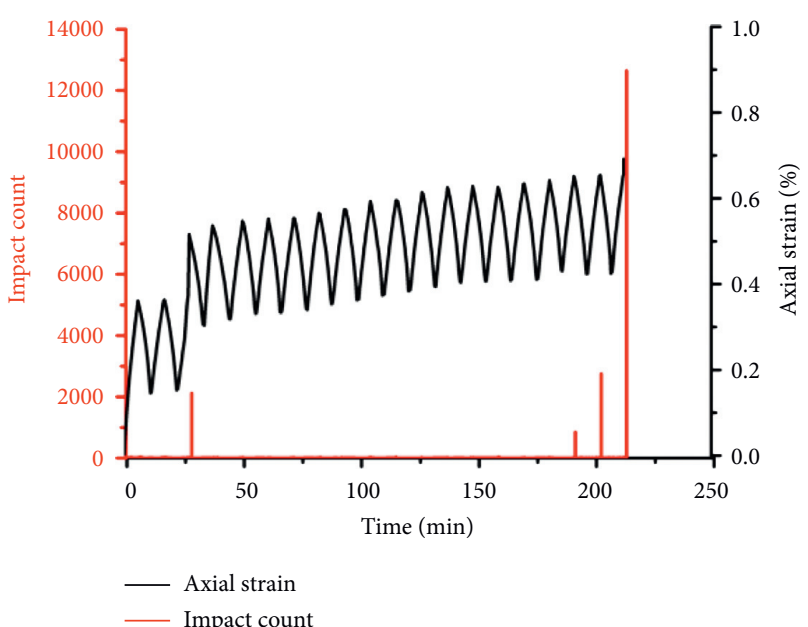

(a)

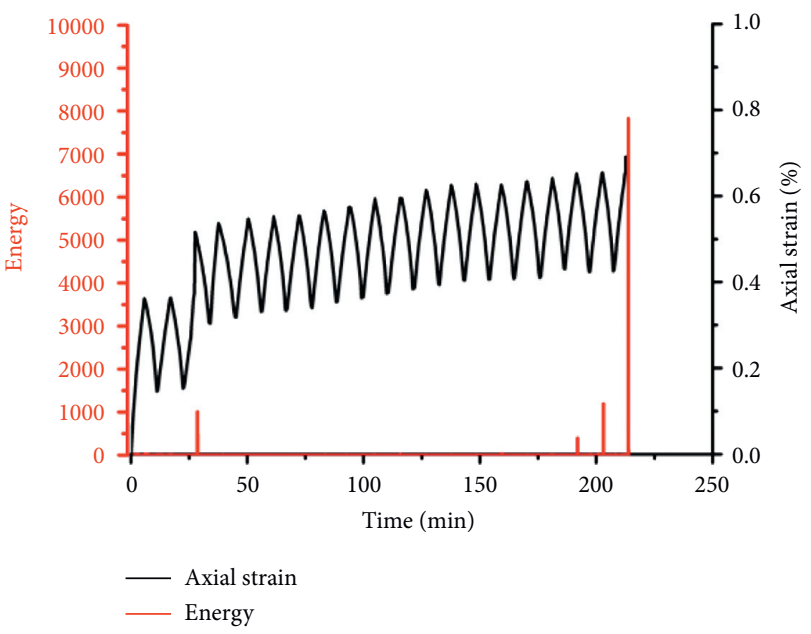

(c)

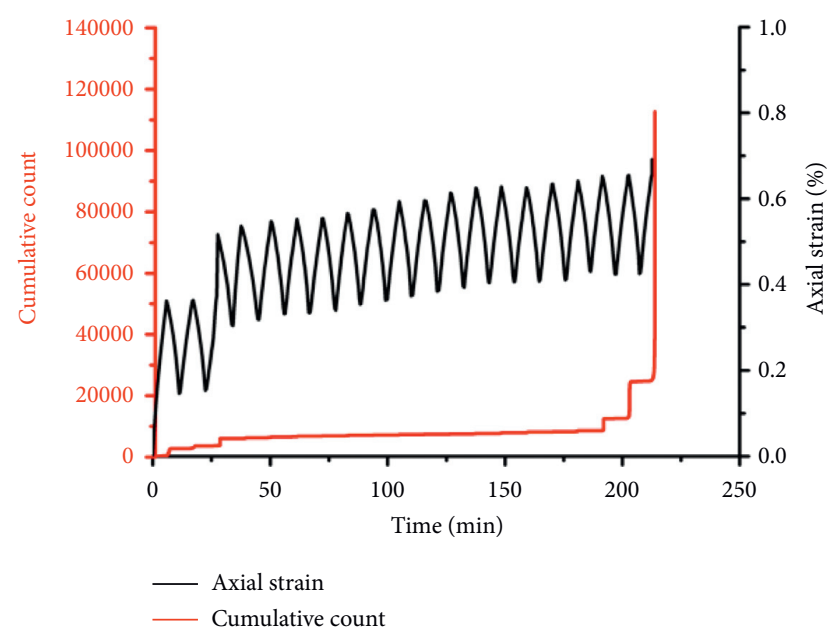

(b)

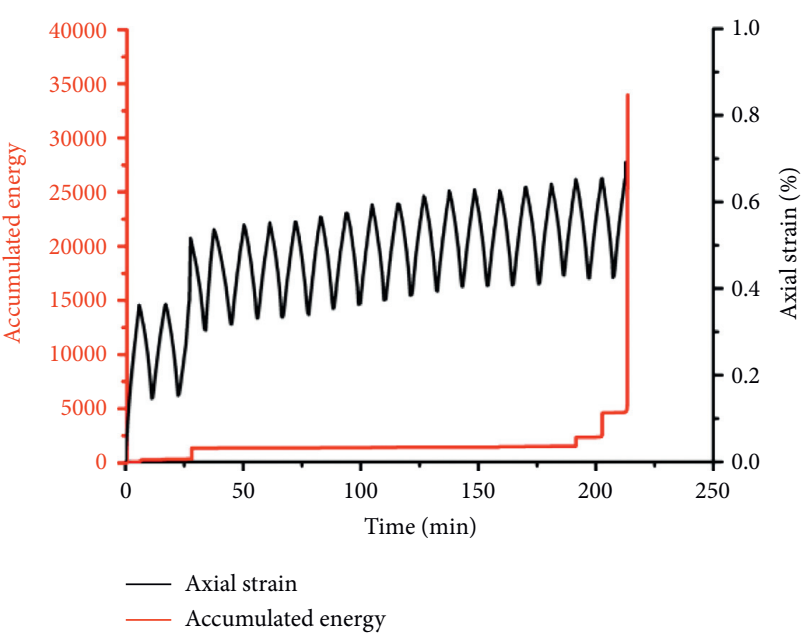

(d)

FiguRE 16: Deformation and acoustic emission characteristics of S-2-2 sample. (a) The curves of ringing count and axial strain of S-2-2 sample with time. (b) The curves of cumulative ringing count and axial strain of S-2-2 sample with time. (c) The curves of energy and axial strain of S-2-2 sample with time. (d) The curves of cumulative energy and axial strain of S-2-2 sample with time.

\section{Mechanical Properties of Rock under Cyclic Loading and Unloading}

Abandoned coal mines used as reservoirs in pumped storage power stations play the role of peak cutting, frequency modulation, and emergency standby in a power system. When the power grid is at peak power consumption, the generated surplus power is used to pump the stored water from the lower reservoir to the upper reservoir for energy storage. When the power grid is not at peak power consumption, the stored water of the upper reservoir is released to the lower reservoir for power generation. This operation imposes cyclic loading and unloading on the surrounding rock of the water reservoir.

Axial cyclic loading and unloading experiments are carried out on the sandstone samples using a triaxial testing system. The mechanical properties and AE characteristics of the sandstone under cyclic loading and unloading with varying strengths are examined. The precursory information from stability to failure is obtained, and the relationship between loading and unloading strength and cycle times is summarized, which is significant for stability monitoring and disaster warning for surrounding rocks in similar projects.

4.1. Experimental Process. The strength softening dividing point of sandstone samples is $2 \%$ water content rate (see Table 1). After the water content rate exceeds $2 \%$, the strength softening phenomenon of the sample gradually decreases. The water content rate of sandstone specimens used in the cyclic loading and unloading test is set as $2 \%$. Cyclic loading and unloading tests are carried out using a rock triaxial compression testing system equipped with an acoustic emission acquisition device.

The average uniaxial compressive strength of sandstone samples with $2 \%$ water content rate state is $37.657 \mathrm{MPa}$ (see Table 1). Applying the cyclic loading and unloading test with 


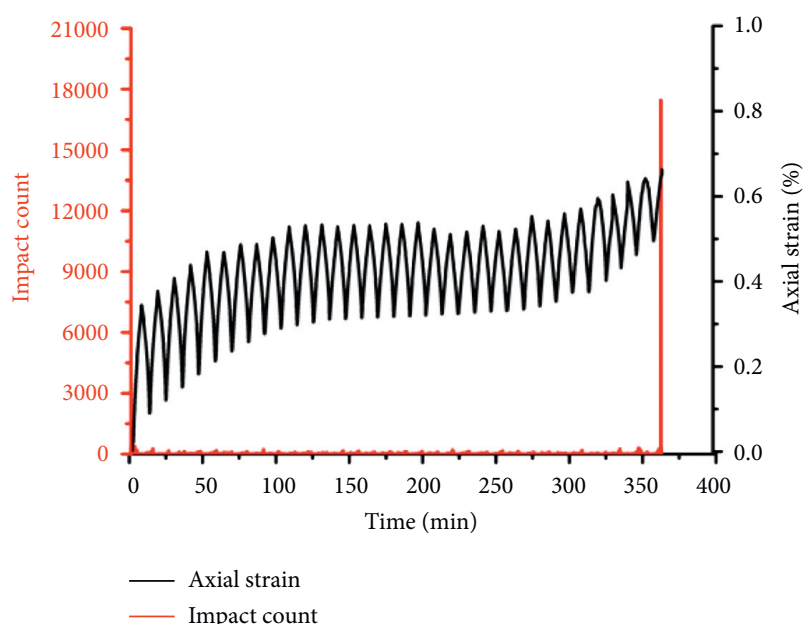

(a)

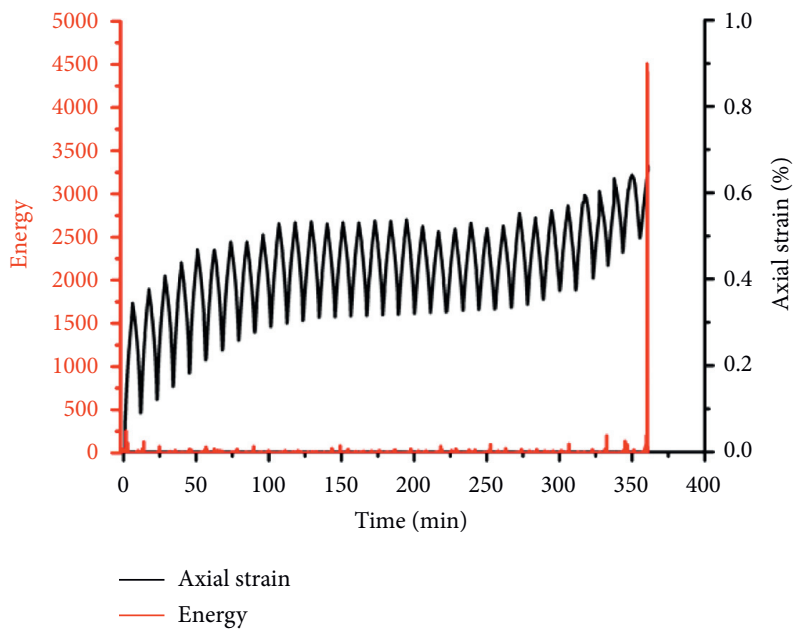

(c)

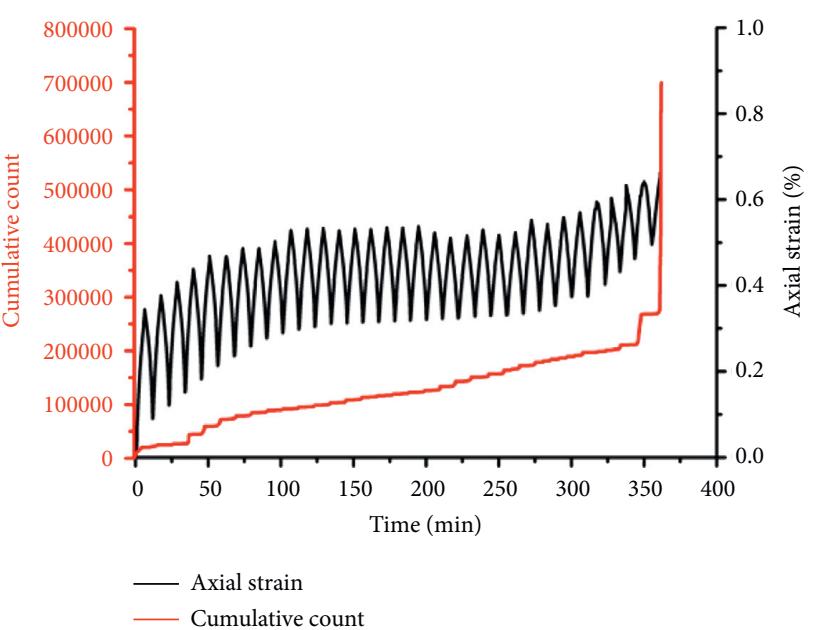

(b)

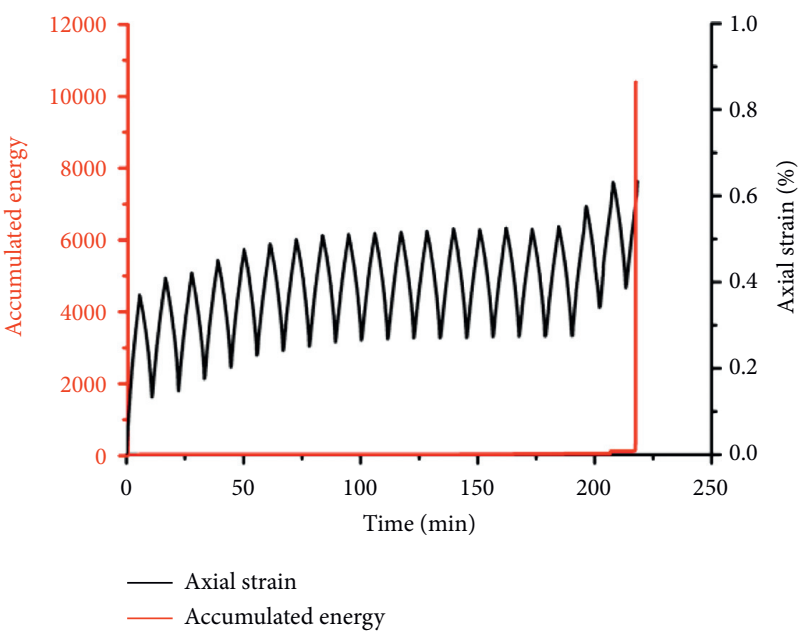

(d)

Figure 17: Deformation and acoustic emission characteristics of S-3-2 sample. (a) The curves of ringing count and axial strain of S-3-2 sample with time. (b) The curves of cumulative ringing count and axial strain of S-3-2 sample with time. (c) The curves of energy and axial strain of S-3-2 sample with time. (d) The curves of cumulative energy and axial strain of S-3-2 sample with time.

a lower limit of $5 \mathrm{MPa}$ and an upper limit of $36 \mathrm{MPa}$ to the sample causes the sample to break after the second cyclic loading and unloading process. The sandstone sample was relatively complete after 70 loading and unloading cycles with a lower limit of $5 \mathrm{MPa}$ and an upper limit of $28 \mathrm{MPa}$. Therefore, three strength gradients of the cyclic loading and unloading test are determined: the lower limit and upper limit of the S-1 group are $5 \mathrm{MPa}$ and $35 \mathrm{MPa}$, respectively; the lower limit and upper limit of the S-2 group are $5 \mathrm{MPa}$ and $32 \mathrm{MPa}$, respectively; the lower limit and upper limit of the S-3 group are $5 \mathrm{MPa}$ and $32 \mathrm{MPa}$, respectively. The stable loading and unloading mode is shown in Figure 11.

\subsection{Experimental Result Analysis}

4.2.1. Strength and Deformation Characteristics Analysis of Rock under Cyclic Loading and Unloading with Different Strengths. Stress-strain curves can reflect the physical and mechanical characteristics and macrodeformation characteristics of sandstone. Some representative axial stress-strain curves of sandstone samples under cyclic loading and unloading tests with varying strengths are shown in Figures 12-14.

The cyclic loading and unloading process of sandstone can be divided into four stages: the microcrack closing and compaction stage, the elastic deformation stage, the plastic deformation stage, and instability failure stage (see Figure 14). In the process of cyclic loading and unloading, the unloading curve is lower than the loading curve, which is due to the previously compacted microcracks and cracks are gradually released, and the elastic deformation is recovered after unloading, but the plastic deformation cannot be recovered.

Under the action of axial cyclic loading and unloading, a plastic hysteresis loop is formed at the intersection between the unloading stress-strain curve and the reloading stressstrain curve. With increasing cycle number, the hysteresis loop transitions from "sparse to dense, then gradually 
transitions back to sparse." With increasing strain, hysteresis loop area transitions from "large to small, then gradually transitions back to large." After the initial loading and unloading of the sample, the internal cracks and fissures gradually close, the rock structure gradually compacts, increasing unrecoverable plastic deformation gradually slows down, each loading and unloading cycle will cause new cumulative damage to the rock sample, the cumulative deformation gradually increases, and the hysteresis loop becomes more and more dense in the direction of strain increase. With increasing loading and unloading times, sample internal damage gradually accumulates, new and existing fractures continue to expand and intersect, the unrecoverable plastic deformation increases rapidly, the cumulative deformation increases faster, and the hysteresis loop becomes wider and larger with increasing strain, resulting in the eventual failure of the sample. The hysteresis loop forms "sharp leaf" shape at the intersection between the unloading stress-strain curve and the reloading stress-strain curve, indicating that the elastic deformation response of the sample is rapid and the plastic deformation is small when the external disturbance load is reversed.

The average cycle numbers and the failure point strains of samples under cyclic loading and unloading of different strength are given in Table 2.

When the upper stress limit is $35 \mathrm{MPa}$, the cycle number is four, and the average strain at rock failure is $7.4 * 10^{-3}$; when the upper stress limit is $33.5 \mathrm{MPa}$, the cycle number is 20 , and the average strain of rock failure is $6.8 * 10^{-3}$; when the upper stress limit is $32 \mathrm{MPa}$, the cycle number is 38 , and the average strain of the rock failure is $6.5 * 10^{-3}$ (see Table 2). The closer the upper limit of the loading stress is to the theoretical peak stress, the greater the damage is to the sample, the faster the cumulative deformation increases, and the greater the strain at rock failure is. Finally the sample is broken after a small number of loading and unloading cycles.

4.2.2. Acoustic Emission Characteristics of Rock under Cyclic Loading and Unloading with Different Strengths. In the cyclic loading and unloading process, a large number of acoustic emission signals are collected during crack generation and expansion. The curve of cumulative ringing count and axial strain with time and the curve of cumulative energy and axial strain with time of representative specimens are shown in Figures 15-17.

(1) Cyclic loading and unloading with a $5 \mathrm{MPa}-35 \mathrm{MPa}$ strength

(2) Cyclic loading and unloading with a $5 \mathrm{MPa}-33.5 \mathrm{MPa}$ strength

(3) Cyclic loading and unloading with a $5 \mathrm{MPa}-32 \mathrm{MPa}$ strength

The acoustic emission ring counts in the first and second stages are relatively small, the $\mathrm{AE}$ energy release value is relatively low, the distribution of acoustic emission activities is quiet and uniform, and the gradients of cumulative ring count curve and cumulative energy curve are almost zero (see Figures 15-17). A large number of tension and shear cracks occur inside the sample in the third stage, and the generation and propagation of cracks are more intense, causing the ring count and $\mathrm{AE}$ energy to increase rapidly with a more dense distribution. The peak values of ring count and AE energy release correspond well to the position of the strain mutation point, and the cumulative energy curve shows multiple growth steps. At this time, the sample produces new cracks and enters the failure stage, and the ring count and energy reach the maximum value. It is worth noting that the axial strain, ring count, and AE energy of sample S-1-2 increased abruptly during the first loading. After two loading and unloading cycles, the axial strain, ring count, and AE energy of S-2-2 increased abruptly in the third loading cycle, which is due to the natural interlayer cracks and new cracks developing along the structural plane during cycle loading and unloading. Local failure of samples results in a sudden increase of ring count and a large amount of $\mathrm{AE}$ energy being instantly released.

\section{Conclusion}

Using abandoned coal mines as reservoirs for pumped storage power stations, a series of uniaxial compression tests and cyclic loading and unloading tests were carried out for sandstone with different water content rates, and the strength softening mechanism, mechanical properties, and energy release regulation of sandstones are examined. The main conclusions are shown as follows:

(1) With increasing water content rate, the uniaxial compressive strength of sandstone decreases following a negative exponential relationship. The $\mathrm{AE}$ signals of sandstone samples with different water content rates have some similarity. Only a small amount of uniformly distributed AE activity is generated in the initial compaction stage. AE signals in the elastic deformation stage are stable and uniform. In the damage evolution stage, AE signals have a dense distribution, and the numerical value is much higher than in the first two stages. The distribution of peak $\mathrm{AE}$ corresponds to the strain mutation point, and the maximum value of $\mathrm{AE}$ activity is distributed in the damage evolution stage. Therefore, acoustic emission can play a role of monitoring and early warning in the construction and operation of abandoned tunnel storage power station.

(2) With increasing water content rate, the maximum and cumulative $\mathrm{AE}$ counts decrease, i.e., natural state count $>2.0 \%$, water content rate count $>3.5 \%$, and water content rate count $>$ saturated state count. With increasing water content rate, the acoustic emission activity signals in sample at the beginning of loading are more obvious, while the position of the $\mathrm{AE}$ peak is gradually delayed compared to the strain mutation point. The precursory information of rock destruction becomes less and less obvious, indicating that increasing water content rate changes the rock 
failure mode, affecting the accuracy of acoustic emission prediction. Thus it can be seen that in the project, for the surrounding rock with high water content, the accuracy of acoustic emission prediction should be detected to determine whether it is suitable to use acoustic emission to detect the operation of the project.

(3) The stable cyclic loading and unloading process of sandstone can be divided into four stages: the microcrack closing and compaction stage, the elastic deformation stage, the plastic deformation stage, and instability failure stage. A "sharp leaf" plastic hysteresis loop is formed at the intersection between the unloading stress-strain curve and the reloading stress-strain curve. With increasing cycle number, the hysteresis loop moves towards the direction of increasing strain, and the area of hysteresis loop changes "from big to small, then gradually to big.."

(4) The closer the upper limit of the loading stress is to the theoretical peak stress, the greater the damage is to the sample, the faster the cumulative deformation increases, and the greater the strain at rock failure is. Finally, the sample fails after a small number of loading and unloading cycles. In the loading and unloading process, a large number of acoustic emission signals are generated, and the acoustic emission activity in the microcrack closure and compression stage and the elastic deformation stage is relatively small. In the plastic deformation stage, the acoustic emission activity is strong, and the peak values of ring count and $\mathrm{AE}$ energy release correspond to the strain mutation point position. During the instability failure stage, the ring count and instantaneous release energy reach the maximum value. The experimental results provide reference and theoretical guidance for the application of acoustic emission technology in monitoring the safety of energy storage caverns and other projects.

\section{Data Availability}

The experimental data used to support this study are available from the first author upon request.

\section{Conflicts of Interest}

The authors declare that there are no conflicts of interest regarding the publication of this paper.

\section{Acknowledgments}

The first author is grateful to the Chinese Scholarship Council and the University of Western Australia for providing an opportunity to conduct this research as a joint Ph.D. Student. This research was funded by China Postdoctoral Science Foundation, under grant no. 2019M661622.

\section{References}

[1] H. H. Li, B. B. Xu, M. A. Mahmud, D. Y. Chen, and J. J. Zhang, "Pumping phase modulation analysis for operational quality of a pumped-storage generating system," Energy Conversion and Management, vol. 199, p. 111989, 2019.

[2] D. Z. Ren, D. S. Zhou, D. K. Liu, F. J. Dong, S. W. Ma, and H. Hai, "Formation mechanism of the Upper Triassic Yanchang Formation tight sandstone reservoir in Ordos Basin-Take Chang 6 reservoir in Jiyuan oil field as an example," Journal of Petroleum Science and Engineering, vol. 178, pp. 497-505, 2019.

[3] N. Zhang, W. Liu, Y. Zhang, P. F. Shan, and X. L. Shi, "Microscopic pore structure of surrounding rock for underground strategic petroleum reserve (SPR) caverns in bedded rock salt," Energies, vol. 13, no. 7, 2020.

[4] Y. Wu, T. Zhang, C. Xu et al., "Location selection of seawater pumped hydro storage station in China based on multi-attribute decision making," Renewable Energy, vol. 139, pp. 410-425, 2019.

[5] J. C Cui, "Study on the planning and sustainable development of pumped storage power station," International Journal Hydroelectric Energy, vol. 3, pp. 80-82, 2008.

[6] J. Menéndez, F. Schmidt, H. Konietzky et al., "Stability analysis of the underground infrastructure for pumped storage hydropower plants in closed coal mines," Tunnelling and Underground Space Technology, vol. 94, p. 103117, 2019.

[7] T. Jiang, X. Pan, M. Ren, M. Ren, J. Lei, and J. Dong, "Analysis of rock alteration in a hydropower engineering project, southeastern China," Arabian Journal of Geosciences, vol. 12, no. 8, 2019.

[8] G. Feng, Y. Kang, X. C. Wang et al., "Investigation on the Failure characteristics and fracture classification of shale under brazilian test conditions," Rock Mechanics and Rock Engineering, vol. 53, no. 7, pp. 3325-3340, 2020.

[9] G. Feng, X. C. Wang, M. Wang, and Y. Kang, "Experimental investigation of thermal cycling effect on fracture characteristics of granite in a geothermal-energy reservoir," Engineering Fracture Mechanics, vol. 235, Article ID 107180, 2020.

[10] H. Huang, T. Babadagli, X. Chen, H. Z. Li, and Y. M. Zhang, "Performance comparison of novel chemical agents for mitigating water-blocking problem in tight gas sandstones," SPE Reservoir Evaluation \& Engineering, vol. 2020, pp. 1-9, 2020.

[11] Y. Zhang, S. G. Cao, N. Zhang, and C. Z. Zhao, "The application of short-wall block backfill mining to preserve surface water resources in northwest China," Journal of Cleaner Production, vol. 261, Article ID 121232, 2020.

[12] P. F. Shan and X. P. Lai, "An associated evaluation methodology of initial stress level of coal-rock masses in steeply inclined coal seams, Urumchi coal field, China," Engineering Computations, vol. 37, no. 6, pp. 2177-2192, 2020.

[13] C. X. Wang, P. T. Shen, J. T. Chen et al., "Compression characteristics of filling gangue and simulation of mining with gangue backfilling: an experimental investigation," Geomechanics and Engineering, vol. 20, no. 6, pp. 485-495, 2020.

[14] M. K. Jafari, F. Pellet, M. Boulon, and K. A. Hosseini, "Experimental study of mechanical behaviour of rock joints under cyclic loading," Rock Mechanics and Rock Engineering, vol. 37, no. 1, pp. 3-23, 2004.

[15] S. Yang, N. Zhang, X. Feng, J. Kan, D. Pan, and D. Qian, "Experimental investigation of sandstone under cyclic loading: damage assessment using ultrasonic wave velocities and 
changes in elastic modulus," Shock and Vibration, pp. 1-13, 2018.

[16] D. K. Liu, Z. L. Gu, R. X. Liang et al., "Impacts of pore-throat system on fractal characterization of tight sandstones," Geofluids, vol. 2020, Article ID 4941501, 17 pages, 2020.

[17] S. C. Hu, Y. L. Tan, H. Zhou et al., "Anisotropic modeling of layered rocks incorporating planes of weakness and volumetric stress," Energy Science \& Engineering, vol. 8, no. 3, 2020.

[18] S. J. Chen, D. W. Yin, N. Jiang, F. Wang, and Z. H. Zhao, "Mechanical properties of oil shale-coal composite samples," International Journal of Rock Mechanics and Mining Sciences, vol. 123, Article ID 104120, 2019.

[19] S. Song, X. Liu, Y. Tan, D. Fan, Q. Ma, and H. Wang, "Study on failure modes and energy evolution of coal-rock combination under cyclic loading," Shock and Vibration, pp. 1-16, 2020.

[20] Q. B. Meng, M. W. Zhang, and Z. Z. Zhang, "Research on non-linear characteristics of rock energy evolution under uniaxial cyclic loading and unloading conditions," Environmental Earth Sciences, vol. 78, no. 23, p. 650, 2019.

[21] Q. Meng, M. Zhang, L. Han, H. Pu, and Y. Chen, "Acoustic emission characteristics of red sandstone specimens under uniaxial cyclic loading and unloading compression," Rock Mechanics and Rock Engineering, vol. 51, no. 4, pp. 969-988, 2018.

[22] F. Pei, H. G. Ji, and T. Z. Zhang, "Energy evolution and mechanical features of granite subjected to triaxial loadingunloading cycles," Advances in Civil Engineering, vol. 19871424 pages, 2019.

[23] S.-Q. Yang, P. Xu, P. G. Ranjith, G.-F. Chen, and H.-W. Jing, "Evaluation of creep mechanical behavior of deep-buried marble under triaxial cyclic loading," Arabian Journal of Geosciences, vol. 8, no. 9, pp. 6567-6582, 2015.

[24] X. Liu, X. Wang, E. Wang, Z. Liu, and X. Xu, "Study on ultrasonic response to mechanical structure of coal under loading and unloading condition," Shock and Vibration, pp. 1-12, 2017.

[25] J. Xu, J. Jiang, L. Zuo, and Y. Gao, "Acoustic emission monitoring and failure precursors of sandstone samples under various loading and unloading paths," Shock and Vibration, pp. 1-11, 2017.

[26] B. Zhao, D. Liu, T. Huang, W. Huang, and W. Liu, "Mechanical behavior of red sandstone under incremental uniaxial cyclical compressive and tensile loading," Shock and Vibration, pp. 1-10, 2017.

[27] J. Chen, C. Du, D. Jiang, J. Fan, and Y. He, “The mechanical properties of rock salt under cyclic loading-unloading experiments," Geomechanics and Engineering, vol. 10, no. 3, pp. 325-334, 2016.

[28] M. He, N. Li, Y. Chen, and C. Zhu, "Strength and Fatigue Properties of Sandstone under Dynamic Cyclic Loading," Shock and Vibration, pp. 1-8, 2016.

[29] D. Liu, Z. Wang, X. Zhang, Y. Wang, X. Zhang, and D. Li, "Experimental investigation on the mechanical and acoustic emission characteristics of shale softened by water absorption," Journal of Natural Gas Science and Engineering, vol. 50, pp. 301-308, 2018.

[30] H. Guo, B. Li, Y. Zhang, X. Wang, and F. Zhang, "Hydrophilic characteristics of soft rock in deep mines," International Journal of Mining Science and Technology, vol. 25, no. 2, pp. 177-183, 2015.
[31] E. Broch, "Changes in rock strength caused by water," International Journal of Rock Mechanics and Mining Sciences \& Geomechanics Abstracts, vol. 17, no. 3, p. 42, 1980.

[32] H. Guo, M. He, C. Sun, B. Li, and F. Zhang, "Hydrophilic and strength-softening characteristics of calcareous shale in deep mines," Journal of Rock Mechanics and Geotechnical Engineering, vol. 4, no. 4, pp. 344-351, 2012.

[33] M. Y. Çelik, "Water absorption and P-wave velocity changes during freeze-thaw weathering process of crosscut travertine rocks," Environmental Earth Sciences, vol. 76, no. 12, 2017.

[34] N. Jiang, C. X. Wang, H. Y. Pan et al., "Modeling study on the influence of the strip filling mining sequence on mining-induced failure," Energy Science \& Engineering, vol. 8, pp. 2239-2255, 2020.

[35] F. Ren, C. Zhu, and M. He, "Moment tensor analysis of acoustic emissions for cracking mechanisms during schist strain burst," Rock Mechanics and Rock Engineering, vol. 53, no. 1, pp. 153-170, 2020.

[36] Y. Lu, L. Wang, X. Sun, and J. Wang, "Experimental study of the influence of water and temperature on the mechanical behavior of mudstone and sandstone," Bulletin of Engineering Geology and the Environment, vol. 76, no. 2, pp. 645-660, 2016.

[37] X. Wang, W. Yuan, Y. T. Yan, and X. Zhang, "Scale effect of mechanical properties of jointed rock mass: A numerical study based on particle flow code," Geomechanics and Engineering, vol. 21, no. 3, pp. 259-268, 2020. 